\title{
De embudos, filtros y brújulas: economía, técnica y subjetividad en Spotify
}

Lucas Bazzara ${ }^{1}$

Recibido: 10/03/2021; Aceptado: 26/04/2021

Cómo citar: Bazzara, L. (2021) De embudos, filtros y brújulas: economía, técnica y subjetividad en Spotify. Revista Hipertextos, 9 (15), 47-82. DOI: https:// doi.org/10.24215/23143924e028

Resumen. En el presente trabajo se optará por hacer un análisis en profundidad de Spotify, por tratarse de la máxima referencia entre las plataformas de streaming musical, hecho que se constata en su masividad de uso y posición de mercado. Esto no impedirá dar una definición lo suficientemente abarcativa que remita a las plataformas de streaming musical en general, pero tal definición funcionará como punto de partida desde el cual se examinará en detalle su caso económica y culturalmente más emblemático. De esta suerte, y sobre la base de la articulación que opera en Spotify entre economía, técnica y subjetividad, las preguntas que guiarán el desarrollo del trabajo serán: ¿Cuál es su modelo de negocios, o qué lógica de mercado pone en juego? ¿Cuál es su modelo subjetivo, o qué tipo de usuario u oyente ideal configura? Y ¿De qué tecnologías computacionales se vale para unir los intereses de las industrias y los usuarios? Como se verá, términos como freemium, machine learning, sistema de recomendación, perfil y personalización resultarán claves para desentrañar esta lógica de plataforma.

Palabras Clave: Spotify, modelo de negocio, modelos algorítmicos, perfil, personalización.

Sumario. 1. Introducción. 2. Modelo económico: entre la gratuidad y el pago, entre el crecimiento y la supervivencia. 3. Modelo subjetivo: algoritmos de recomendación personalizada para el usuario (in)dividuado como perfil. 4. Conclusiones.

\section{Of funnels, filters and compasses: economy, technique and subjectivity in Spotify}

Abstract. In this paper we will do an in-depth analysis of Spotify, as it is the maximum reference among music streaming platforms, a fact that can be seen in its massive use and market position. This will not preclude giving a sufficiently comprehensive definition that refers to music streaming platforms in general, but such a definition will function as a starting point from which the most emblematic economic and cultural case will be examined in detail. In this way, and based on the articulation that operates in Spotify between economics, technique and subjectivity, the questions that will guide the development of

1 Magíster en Comunicación y Cultura y Licenciado en Ciencias de la Comunicación por la Universidad de Buenos Aires, Becario Doctoral en Ciencias Sociales de la Agencia Nacional de Promoción Científica y Tecnológica (ANPCy'T).Contacto: lucas.bazzara@gmail.com 
the work will be: What is its business model, or what market logic does it put into play? What is its subjective model, or what type of ideal user or listener does it configure? And what computing technologies does it use to "unite the interests of industries and users"? As you will see, terms such as freemium, machine learning, recommendation system, profile and personalization will be key to unraveling this platform logic.

Keywords: Spotify, business model, algorithmic models, profile, personalization.

\section{De funis, filtros e bússolas: economia, técnica e subjetividade no Spotify}

Resumo. Neste trabalho opta-se por fazer uma análise aprofundada do Spotify, pois é a referência máxima entre as plataformas de streaming de música, facto que pode ser visto em seu uso massivo e posição de mercado. Isso não impede que seja dada uma definição suficientemente abrangente que se refere às plataformas de streaming de música em geral, mas tal definição funcionará como um ponto de partida a partir do qual seu caso econômico e cultural mais emblemático será examinado em detalhes. Dessa forma, e a partir da articulação que opera no Spotify entre economia, técnica e subjetividade, as questões que nortearão o desenvolvimento do trabalho serão: Qual é o seu modelo de negócio, ou qual lógica de mercado ele põe em jogo? Qual é o seu modelo subjetivo ou que tipo de usuário ou ouvinte ideal você configura? E quais tecnologias computacionais ele usa para "unir os interesses de indústrias e usuários"? Como você verá, termos como freemium, aprendizado de máquina, sistema de recomendação, perfil e personalização serão fundamentais para desvendar essa lógica de plataforma.

Palavras-chave: Spotify, modelo de negócio, modelos algorítmicos, perfil, personalização. 
Nuestra escala nos proporciona datos únicos que permiten una experiencia diferenciada y personalizada. Muchos servicios de música en streaming tienen grandes catálogos, pero creemos que Spotify se diferencia del resto porque proporcionamos a los usuarios una experiencia más personalizada, impulsada por potentes motores de búsqueda y descubrimiento de música. Tenemos una amplia y creciente base de usuarios que están muy comprometidos con Spotify, lo que nos permite aprender continuamente sobre sus comportamientos auditivos a lo largo del día. Utilizamos esta información para crear una experiencia más

personalizada y atractiva para cada nueva visita a nuestra plataforma. Creemos que esta experiencia personalizada es una ventaja competitiva clave, ya que los usuarios son más propensos a interactuar con

una plataforma que refleja su estado de ánimo y actividades en tiempo real y captura una comprensión única de los momentos de su vida. Este profundo conocimiento de nuestros usuarios también nos ayuda a adaptar el contenido, la publicidad, el marketing y la agrupación de productos de manera efectiva. Nuestro objetivo es seguir utilizando los datos y nuestros algoritmos patentados para mejorar la experiencia auditiva, al tiempo que impulsamos el descubrimiento de contenido artístico en nuestra plataforma.

(Declaración de Registro presentada por la compañía Spotify Technology S.A. ante la Comisión de Bolsa y Valores de Estados Unidos, Prospectus)

Spotify, por caso, resume años de búsquedas analógicas de música en una base de datos inmensa que "individualiza" a su consumidor, tanto como ese consumidor se deja "individualizar" por Spotify. Las comillas tienen su sentido: no se trata de la identificación de un individuo, único e irrepetible, sede de una singularidad, sino del hecho de que eso que se individualiza es el resultado de las buisquedas estadísticas de millones de "personas" que permiten saber qué desea "esa" persona porque ese deseo emana de una función estadística que, cuantos más datos generales tiene, mejor puede identificar sus targets. El hecho fundamental en todo este proceso es que lo dividual como modo de subjetivación "activo" se realiza en una compleja interactividad con máquinas que aprenden, modifican su comportamiento y comunican con una precisión encomiable: máquinas casi bumanas. Máquina, epistémicamente bablando.

(Pablo Rodríguez, Las palabras en las cosas)

\section{Introducción}

En la Declaración de Registro presentada ante la Comisión de Bolsa y Valores de Estados Unidos, documento público requerido a toda empresa que pretenda comenzar a cotizar en la Bolsa de Valores de Nueva York, Spotify Technology S.A. (2018) dice especializarse en la construcción de "un mercado de música de dos lados": "para usuarios y artistas" (p. 98)2. De esos dos lados, en función del propósito del presente trabajo, nos limitaremos y dedicaremos al análisis del primero: el mercado de música para usuarios. De lo que se trata es de echar luz sobre las dos puntas del mentado sintagma: el mercado del streaming musical y sus usuarios. Si bien partiremos de una definición general de las plataformas de streaming musical apuntalada en los aportes de Eriksson et al. (2019) y Srnicek (2018), ello nos servirá de puntapié para desarrollar un análisis de Spotify en particular, por tratarse del caso más emblemático desde el punto de vista de la adopción social y la posición de mercado. De acuerdo con el investigador sueco Patrick Vonderau (2017), Spotify "se ha convertido en un modelo para otros servicios que utilizan tecnología digital para transformar la distribución de bienes culturales" (p. 2), pudiéndose

\footnotetext{
2 Siempre que en la bibliografía se indique una referencia en inglés, querrá decir que el texto citado cuenta con una traducción propia.
} 
mencionar, por ejemplo, que "entre 2007 y 2013, más de 180 compañías agregaron el sufijo ify a su marca" (p. 2), siendo de entre ellas quizás Cabify, el servicio de plataforma para el transporte de personas, el nombre más conocido para nosotros. En este sentido creemos, con Eriksson (2018), que Spotify "administra" en la actualidad las prácticas de escucha de centenas de millones de personas -comparativamente más que cualquier otra plataforma- y, al mismo tiempo, que ejemplifica cómo la tecnología de streaming está altamente capitalizada y opera a escalas masivas bajo las condiciones contemporáneas de una economía globalizada.

Si bien con esta decisión se opta por resignar el estudio de las especificidades propias de cada plataforma con sus consiguientes puestas en contacto y contraste, se gana no obstante en el conocimiento en profundidad y detalle de una evolución en el tiempo, una lógica de funcionamiento y una dinámica de las relaciones entre subjetividad, técnica y economía que un análisis comparativo no podría sino marginar. Haremos el recorrido en dos grandes apartados, atendiendo en el primero de ellos a la conformación del modelo económico, comúnmente denominado freemium, y que como se verá hace las veces de embudo entre las cuentas gratuitas y las pagas. En el segundo apartado se atenderá a la configuración del modelo subjetivo, para cuya comprensión resultará esencial dar cuenta del sistema de recomendación de la plataforma y de los filtros algorítmicos que utiliza, así como de las asistencias personalizadas que como brújulas orientativas emanan del sistema de recomendación. Ello nos permitirá desmontar lo que denominaremos el constructo tecno-económico mediado por las actividades de los sujetos o, dicho con otras palabras, la triangulación de plataforma entre usuarios, tecnologías computacionales y mercado.

\section{Modelo económico: entre la gratuidad y el pago, entre el crecimiento y la supervivencia}

\subsection{Una mención general sobre las plataformas digitales}

En Capitalismo de plataformas Nick Srnicek (2018) sostiene que "podemos aprender mucho acerca de las empresas de tecnología más importantes tomándolas como actores económicos dentro de un modo capitalista de producción" (p. 10). Ese será el foco del análisis en este apartado. Pero antes de adentrarnos en ello resultará oportuno precisar una definición de la noción de plataforma. Si tomamos la definición que ofrece Srnicek, se puede definir a las plataformas de la siguiente manera:

En el nivel más general, las plataformas son infraestructuras digitales que permiten que dos o más grupos interactúen. De esta manera, se posicionan como intermediarias que reúnen a diferentes usuarios: clientes, anunciantes, proveedores de servicios, productores, distribuidores e incluso objetos físicos. Casi siempre, estas plataformas también vienen con una serie de herramientas que permiten a los usuarios construir sus propios productos, servicios y espacios de transacciones (...). Las plataformas, en resumidas cuentas, son un nuevo tipo de empresa... mucho más que empresas de Internet o empresas de tecnología, dado que pueden operar en cualquier parte, donde sea que tenga lugar la interacción digital. (Srnicek, 2018, p. 45, 47) 
De acuerdo con Eriksson et al. (2019), el término plataforma se utiliza en la industria informática desde mediados de la década de 1990, cuando Microsoft empieza a describir Windows como una plataforma. "Después de circular primero -sostienen los autores- dentro de los estudios de administración y organización, el término ingresa a la investigación de medios simultáneamente con el surgimiento de la noción de Web 2.0” (p. 12). Y -agregan- si bien no hay en la actualidad una definición categórica o uniformemente extendida, existe sin embargo una tendencia a entender el término como "el eslabón perdido entre la computación y los negocios, un mercado en línea [online] que une los intereses de las industrias y los usuarios" (p. 12). Así entendidas, las plataformas serían constructos tecno-económicos mediados por las actividades de los usuarios. Como "terreno" sobre el que tienen lugar las actividades de y entre los usuarios, las plataformas se convierten en el espacio digital privilegiado para el registro (por lo general privado) de la totalidad de los datos que emanan de esas actividades.

Si los datos se han convertido en los últimos años en un factor clave para el funcionamiento y desarrollo de las plataformas digitales, la razón económica detrás de este acoplamiento, argumenta Srnicek (2018), es que "con una prolongada caída de la rentabilidad de la manufactura, el capitalismo se volcó hacia los datos como un modo de mantener el crecimiento económico y la vitalidad de cara al inerte sector de la producción” (p. 13). Desde esta perspectiva, las plataformas digitales habrían emergido como un nuevo modelo de negocios que, frente al estancamiento de la productividad basada en el intercambio de bienes, se presenta como el rostro de un aparato productivo de nuevo tipo, donde los datos fungirían de insumos para su extracción y explotación, y las actividades de los usuarios serían "la fuente natural de esta materia prima" (Srnicek, 2018, p. 42). Dentro de este nuevo modelo de negocios llamado plataforma, sus distintos tipos desarrollan diferentes modos de tratamiento de esos datos (diferentes modos de extraerlos, analizarlos, usarlos y/o venderlos) y diferentes modos de organizar y perfilar su economía, con la finalidad de aumentar sus ingresos y obtener una rentabilidad. Más allá de las diferencias entre plataformas, tanto en el tratamiento de los datos como en la búsqueda de ganancias los algoritmos desempeñan un papel central ${ }^{3}$.

Las plataformas de streaming musical serían, desde el punto de vista de la clasificación que hace Srnicek (2018), plataformas on-demand a las que denomina plataformas de productos. Están, de acuerdo con esta clasificación, las plataformas publicitarias (como Google o Facebook, "que extraen información de los usuarios, llevan a cabo un trabajo de análisis y luego usan los productos de ese proceso para vender espacio publicitario"); las plataformas de la nube (como Amazon Web Services, "que son propietarias del hardware y del software de negocios que dependen de lo digital y que los rentan de acuerdo con necesidades"); las plataformas industriales (como General Electric o Siemens, "que producen el hardware y el software que se necesita para transformar la manufactura tradicional en procesos conectados por Internet que bajan los costos de producción

\footnotetext{
${ }_{3}^{3}$ Volveremos sobre el papel de los algoritmos, con profundidad y detalle, en el segundo apartado del presente artículo. Para lo que aquí interesa nos remitimos a la relación que establece Tiziana Terranova (2017) entre algoritmos y capital, según la cual aquellos serían, desde la perspectiva de empresa de las plataformas, simplemente capital fijo, medios de producción optimizados para la obtención de rendimiento económico: "Desde el punto de vista del capitalismo, los algoritmos son principalmente una forma de 'capital fijo', es decir, son simplemente medios de producción. Codifican una cierta cantidad de saber social (extraída de lo que elaboran matemáticos, programadores, y también las actividades de los usuarios), pero no son valiosos por sí mismos. En la economía contemporánea, son valiosos sólo en la medida en que permiten la conversión de tal saber en valor de cambio (monetización) y su (exponencialmente creciente) acumulación (los titánicos cuasimonopolios de la Internet social)" (p. 96).
} 
y transforman bienes en servicios"); las plataformas austeras (como Uber o Airbnb, "que intentan reducir a un mínimo los activos de los que son propietarias y obtener ganancias mediante la mayor reducción de costos posible"); y están finalmente las plataformas de productos, que transforman un bien tradicional en un servicio y cobran por ello "un alquiler o una tasa de suscripción” (p. 50). Vale decir que, más allá de la clasificación analítica, algunos tipos de plataforma comportan igualmente rasgos característicos de algunas de las otras; así por ejemplo, Google sería una plataforma publicitaria que obtiene también ingresos posicionándose como plataforma de la nube (a través de Google Cloud Platform), y que se ha interesado asimismo por el mercado de las plataformas de productos (al lanzar Google Play Music); o bien las del tipo streaming musical, caracterizadas como plataformas de productos on-demand que transforman bienes tradicionales en servicios a cambio de una suscripción, no por ello dejan de extraer información de los usuarios llevando a cabo un trabajo de análisis para hacer redituables los productos de ese proceso, y si bien la venta de espacio publicitario no es allí central, juega de todos modos su papel, como se verá.

De acuerdo con Srnicek (2018), las plataformas de productos son aquellas que, en el universo cada vez más amplio de la economía digital, están en las mejores condiciones de lograr una tendencia a cero del costo marginal (entendido como el costo de producir una unidad más de determinado producto), dado que, al transformar bienes tradicionales en servicios, la distribución del producto digital por canales virtuales, por caso, tiene un costo igual a cero. Según las palabras del autor:

\begin{abstract}
Las plataformas de productos son quizás uno de los medios más importantes a través de los cuales las empresas intentan recuperar la tendencia a cero costos marginales en algunos bienes. La música es el mejor ejemplo, desde que a fines de los años noventa descargar música gratis se volvió tan simple como instalar un programa sencillo. Los ingresos de los sellos discográficos sufrieron una importante caída, dado que los consumidores dejaron de comprar CDS y otras copias físicas de música. Pero, a pesar de sus muchos obituarios, la industria de la música revivió en años recientes gracias a plataformas (Spotify, Pandora) que perciben pagos tanto de quienes escuchan música como de los sellos discográficos y los anunciantes. Entre 2010 y 2014 los servicios de suscripción vieron aumentar la cantidad de usuarios de 8 millones a 41 millones, y los ingresos por suscripción ya están preparados para superar a los ingresos por descargas como la fuente más importante de la música digital. Luego de caer durante años, la industria de la música se preparó para ver crecer nuevamente sus ingresos en 2016. (Srnicek, 2018, p. 68-69)
\end{abstract}

Estas palabras, publicadas originalmente en 2016, fueron corroboradas poco tiempo después, pues según las cifras que anualmente publica la Federación Internacional de la Industria Fonográfica (IFPI, según sus siglas en inglés), 2017 fue el año en que por primera vez los ingresos generados por servicios de streaming musical superaron a los ingresos generados por ventas físicas y descargas (ver Gráfico $\mathrm{N}^{\circ} 1$ ). 
Gráfico $n^{\circ}$ 1: Evolución de ingresos globales de música grabada según formato (19992017)

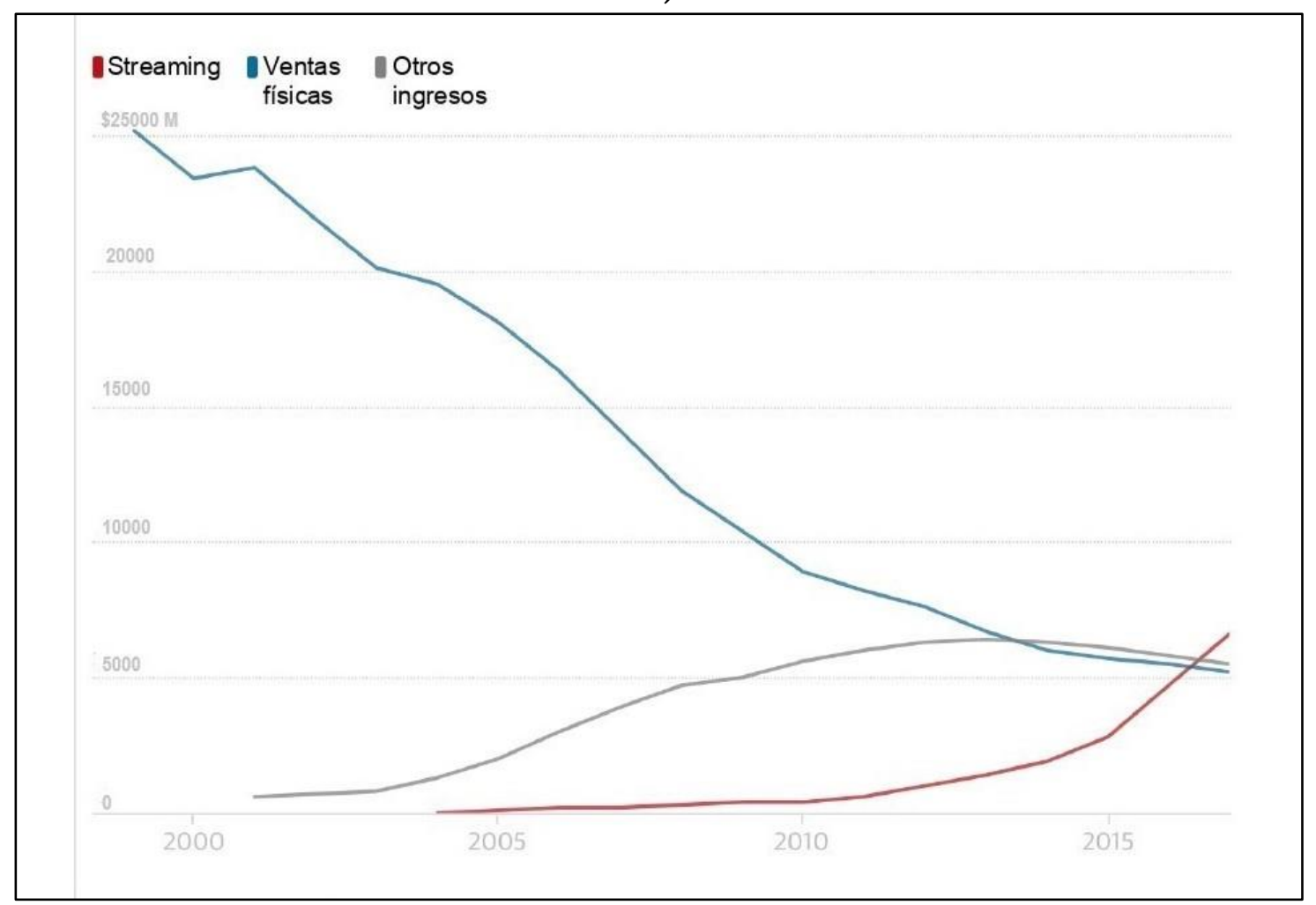

Fuente: Sweney, 2018

Estos números, a su vez, se vieron consolidados en los años siguientes, con una ratificación de ambas tendencias, esto es, alza para aquéllos (servicios de streaming) y baja para éstos (ventas físicas y descargas), según se observa en el último informe anual elaborado por la IFPI que incluye las cifras correspondientes a 2020 (ver Gráfico N²). 


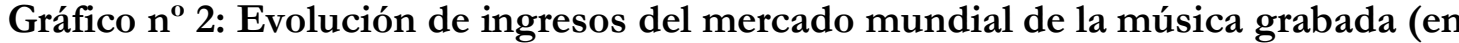 miles de millones de dólares) según formato (2001-2020)}

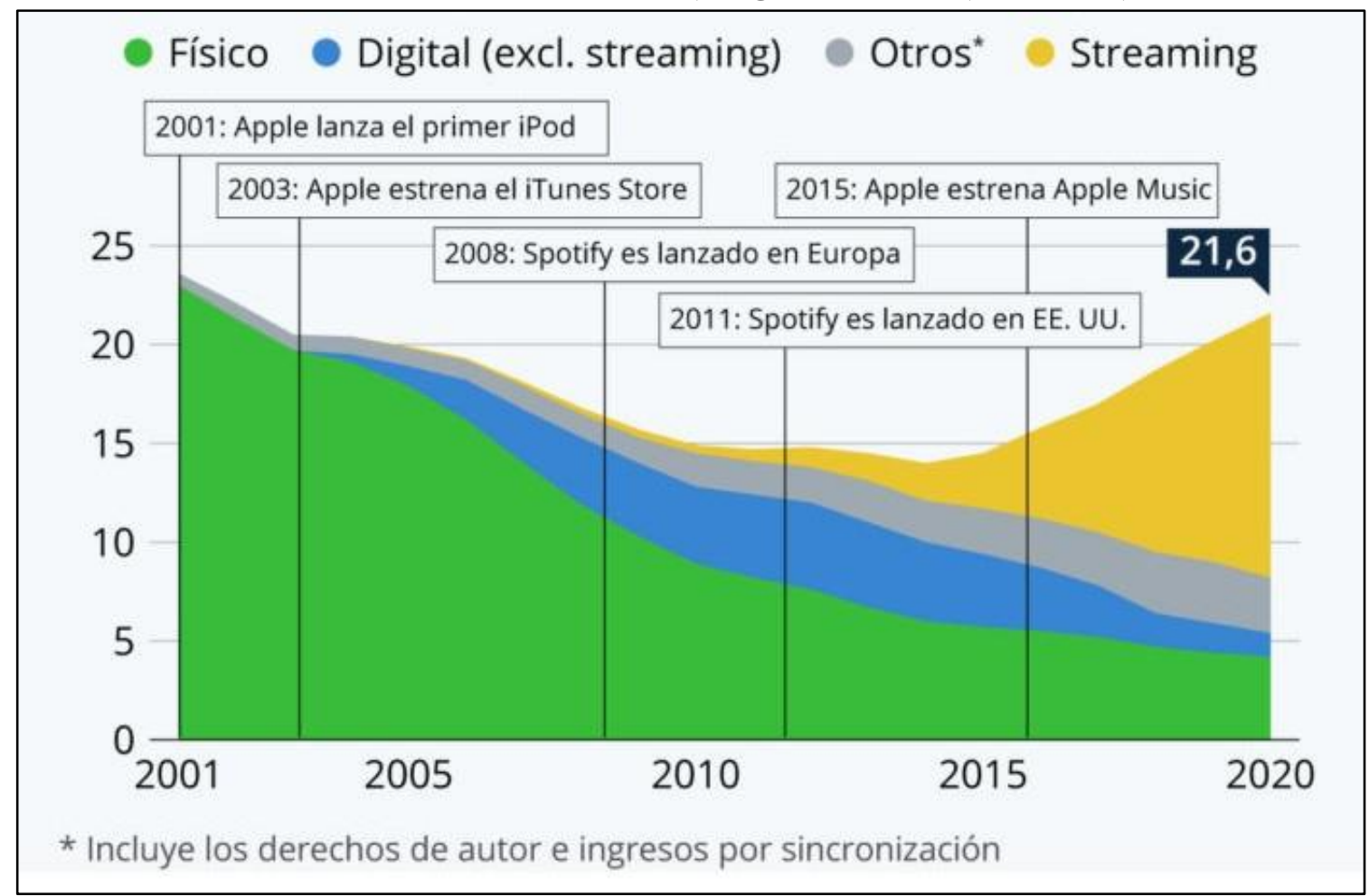

Fuente: Chevalier Naranjo, 2021

Las "cifras del mercado discográfico mundial de 2020", publicadas en el "Informe Mundial de la Música 2021 de la IFPI" bajo el título "El estado de la industria", marcan un crecimiento del mercado de la música grabada del 7,4\% a nivel mundial con relación al año anterior, lo que sumado a los cinco informes anuales previos redundan en un crecimiento por sexto año consecutivo. Si se discrimina este número total, la primera gran segmentación la encontramos entre la comercialización por "venta física" y por "música digital", representando aquélla el 19,5\% de los ingresos globales contra el 67,9\% de esta última. La caída de los ingresos por ventas físicas fue de un 4,7\%, a pesar de la suba de un $23,5 \%$ en la venta de vinilos, ratificándose la tendencia alcista de este formato por décimo quinto año consecutivo. Al interior del segmento "música digital", los servicios de streaming crecieron un 19,9\%, y representan, del total de los ingresos en la actualidad, un 46\% para el caso de las suscripciones pagas y un 16,2\% para el caso de las cuentas con publicidad, lo que significa que del total de la recaudación del mercado de música grabada más de la mitad (el 62,1\%) se obtiene del streaming de audio. En lo que hace a la otra parte de lo que la IFPI denomina "música digital", las descargas retrocedieron un 15,7\% respecto del año anterior y pasaron a conformar el 5,8\% del total del mercado ${ }^{4}$. Finalmente, en cuanto a la segmentación por región, el documento informa que América Latina registró por

\footnotetext{
4 Vale recordar, por último, los segmentos restantes que hacen al total de los ingresos, que corresponden a lo que se denomina "derechos de comunicación al público" (es decir "pagos que se recaudan por la utilización de música grabada en los medios de comunicación y los establecimientos abiertos al público") y "contratos de sincronización" (es decir "ingresos generados por la utilización de música en anuncios publicitarios, películas, videojuegos y televisión”). Estos dos segmentos del mercado tuvieron el primero una caída anual del 10,1\%, y el segundo, que venía de crecer el año anterior, una caída del 9,4\% debido a los retrasos en la producción como consecuencia de la pandemia. Entre ambos representan en la actualidad, respectivamente, el 10,6\% y el 2,0\% de los ingresos totales.
} 
sexto año consecutivo la tasa de crecimiento más alta a nivel mundial, aumentando en un 15,9\% -algo menos que el 18,9\% de crecimiento del año anterior- que se explica fundamentalmente por fuertes ingresos por streaming que, según se destaca, crecieron un 30,2\% en 2020 y llegan a representar prácticamente tres cuartos del mercado, alcanzando una participación del 84,1\% (IFPI, 2021, pp. 6-7-8).

\subsection{La estrategia de embudo: el modelo freemium de crecimiento}

En un trabajo sobre la gestión de productos y contenidos de medios Ángel Arrese (2004) sostiene que:

Las diferencias fundamentales como productos entre un diario gratuito y una película, o entre una obra musical y un programa televisivo, son tan grandes, que cualquier intento de considerarlos unitariamente corre el riesgo de errar. La variada naturaleza de los distintos contenidos de los medios aconseja, por tanto, ser muy cautos a la hora de exponer ideas, teorías o principios de carácter universal. (p. 01)

Esta cautela, creemos, es igualmente aplicable a las plataformas de streaming musical en tanto distribuidoras de contenidos, cuyas diferencias no se encontrarían centralmente en sus respectivos catálogos ${ }^{5}$, sino más bien en las especificidades relativas al modelo de negocios que implementan, así como en el tratamiento de los datos que almacenan y en el diseño de sus interfaces (lo que incluye un modo particular de interpelación y de construcción de un "oyente ideal”). Por ello, más allá de la definición general que con Srnicek (2018) y Eriksson et al. (2019) hemos ofrecido, y por más que por momentos se insista en alguna caracterización de corte más general, haremos foco en Spotify, por tratarse -tanto a nivel local como internacional y a lo largo de la última década- de la máxima referencia en el sector, hecho que se constata a la vez en la masividad de uso y en su posición de mercado (ver Gráfico $\mathrm{N}^{\circ} 3$ ), y que lleva a la empresa a autodefinirse como "el mayor servicio de suscripción de transmisión [streaming] de música a nivel

${ }^{5}$ Con algunas diferencias (entre las que cabe destacar la música de miles de artistas independientes de distintas partes del mundo que deciden subir sus materiales a uno u otro servicio), las plataformas de streaming ofrecen sin embargo un catálogo musical similar. Eriksson et al. (2019) sostienen que la razón detrás de este hecho es simple: todas ellas dependen de un mismo "producto", es decir, una licencia de distribución por la música ofrecida, y ese producto puede ser comprado de una única fuente, que no es otra que las grandes compañías discográficas, globales y cartelizadas: las llamadas Big Three (Universal Music Group, Warner Music Group y Sony Music), dueñas de cerca del 70\% de los ingresos generados por consumo de música grabada. Cabe precisar, por otra parte, que los acuerdos comerciales de las plataformas con las Majors discográficas, así como con el grupo Merlin (asociación de sellos discográficos independientes creada para la gestión de sus derechos en medios digitales), responden a una alianza estratégica pues, de un lado, las plataformas necesitan el catálogo musical de las fonográficas, y del otro, las fonográficas necesitan espacios de distribución digital para aquellas obras de las que son propietarias y/o de las que adquieren un porcentaje (de acuerdo al tipo de contrato establecido con cada artista) por las ganancias derivadas de las reproducciones de escucha y derechos intelectuales. Por último, y en lo que respecta específicamente al caso que nos ocupa, resulta oportuno mencionar que tanto las Big Three como el grupo Merlin son o han sido propietarias parciales de Spotify, ya que como parte de los acuerdos comerciales se han hecho de un porcentaje de las acciones de la empresa a cambio de las licencias de distribución. Así por ejemplo, Universal Music Group tiene actualmente una participación accionaria aproximada del 3,5\% de la compañía con sede en Suecia, mientras Sony Music es propietaria de cerca del 2,5\%; Warner Music Group, por su parte, supo ser propietaria del 1,9\%, pero vendió su participación luego de que Spotify comenzara a cotizar en bolsa en 2018; y lo propio ocurrió con el grupo Merlin, que en el mismo año y por la misma razón se deshizo de su paquete accionario del $0,5 \%$. Para más información sobre este último punto se puede consultar el siguiente enlace: https://industriamusical.es/universal-no-estainteresada-en-vender-sus-acciones-en-spotify/ 
global (...), que creemos es casi el doble de la escala de nuestro competidor más cercano, Apple Music" (Spotify Technology S.A., 2018, p. 97).

\section{Gráfico $n^{\circ}$ 3: Evolución de cantidad de usuarios de pago de las principales plataformas de streaming de audio (2010-2020)}

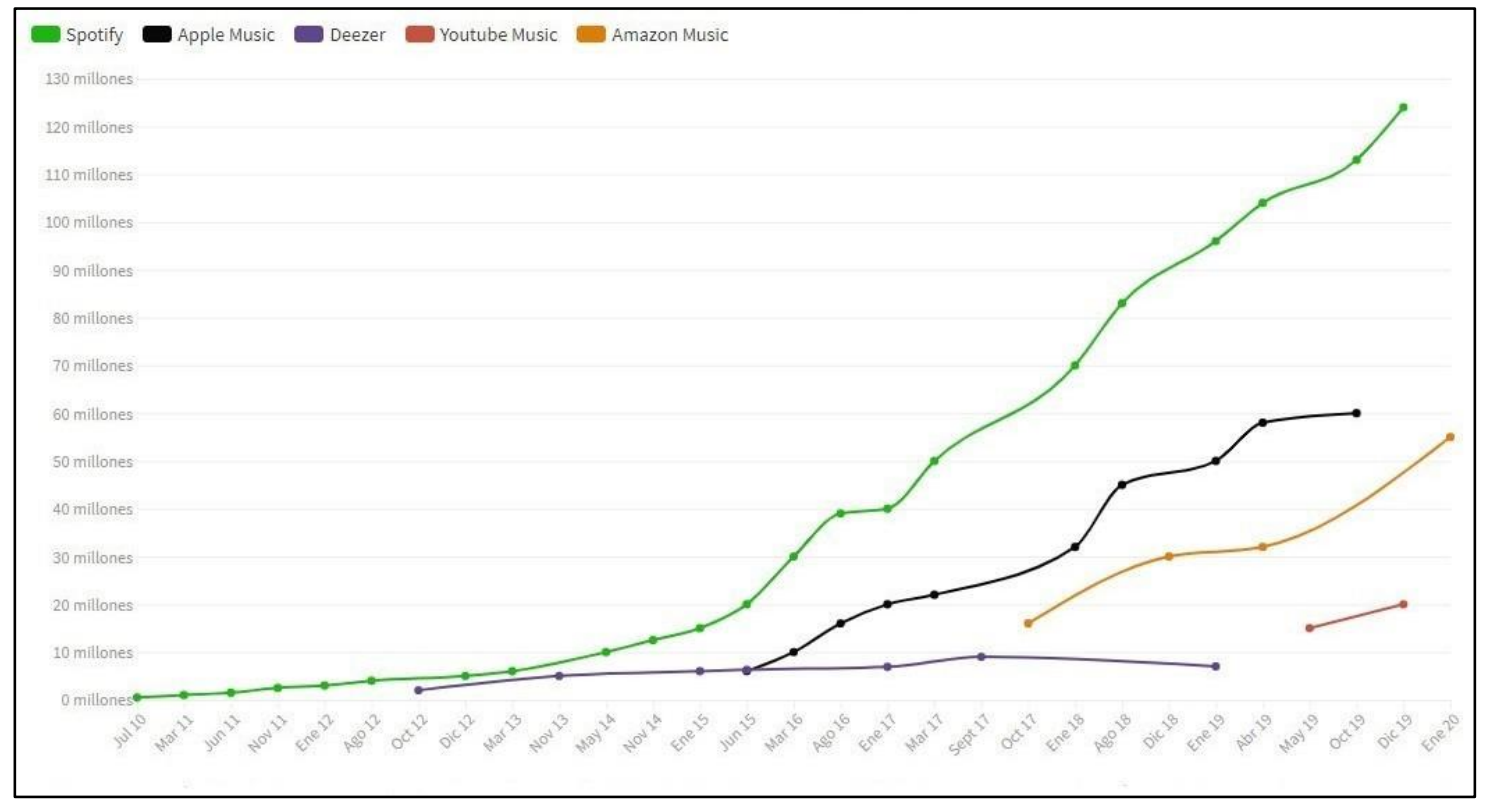

Fuente: García, 2020

Durante el primer trimestre de 2019 Spotify reportó 4 millones de nuevos clientes, lo que le permitió llegar a 100 millones de suscriptores pagos, poco menos que el 50\% de la totalidad de suscripciones que en ese momento ascendía a unos 217 millones de usuarios activos. Dos años después, de acuerdo con el informe "Spotify Tecnología S.A. anuncia los Resultados Financieros Correspondientes al Primer Trimestre de 2021", las suscripciones siguieron en alza: 158 millones de usuarios que pagan por el servicio (lo que representa una suba anual del 21\%) y 208 millones de usuarios gratuitos (que en relación con los 163 millones del año anterior representa un aumento del 27\%), que hacen a un total actual de unos 356 millones de usuarios activos ${ }^{6}$ (registrando un incremento anual del 24\%). Por último, el informe muestra que no sólo el número de usuarios aumenta, también lo hacen los ingresos: en este caso la suba anual fue de $16 \%$, subiendo de $€ 1.848$ a $€ 2.147$ millones (discriminado por tipos de cuenta queda claro cómo los mayores ingresos provienen de las cuentas pagas frente a las gratuitas con publicidad, con números que ascienden a $€ 1.931$ millones para las primeras -lo que representa un $90 \%$ de los ingresos- y a $€ 216$ millones para las segundas -que representan un 10\% de los ingresos) (Spotify Investors, 2021).

Estos datos nos hablan de dos temas centrales: por un lado del crecimiento de Spotify (en número de usuarios y en ingresos) y por otro de su modelo de negocios, conocido como freemium

\footnotetext{
${ }^{6}$ Spotify no publica datos a nivel país, por lo que no nos es posible saber qué porcentaje del total de usuarios corresponde a suscripciones en Argentina. Sin embargo, sí lo hace a nivel regional, y los datos en este sentido arrojan que América Latina comprende el 22\% del total de los usuarios activos a nivel mundial y el 20\% del total de suscriptores Premium a nivel mundial, según informa la Agencia de Comunicación de la empresa para la región Cono Sur.
} 
(neologismo que resulta de la combinación de las palabras inglesas "free" y "premium"), es decir, la oferta simultánea de un servicio básico gratuito y un servicio pago más amplio o avanzado. Si las plataformas digitales, como adelantábamos más arriba con Srnicek (2018), suponían ya de manera general la emergencia de un nuevo modelo de negocios frente al estancamiento de la productividad basada en el intercambio de bienes, entonces aquí la lógica económica de Spotify se presenta como un rasgo específico al interior de ese modelo, una veta particular, entre otras posibles en el universo de plataformas, en la búsqueda de crecimiento y rentabilidad. El modelo freemium, que obtiene sus ingresos a través de la publicidad para los usuarios que no pagan por el servicio y a través del pago de suscripción para quienes tienen una cuenta con abono, apuesta por un ingreso masivo de usuarios "free" que una vez en la plataforma puedan ser seducidos a convertirse en usuarios "premium". Así lo sintetiza Patrik Wikström (2014) en un estudio sobre "la industria musical en una era de distribución digital":

La lógica del modelo de servicio freemium es que los usuarios se sentirán atraídos por el servicio gratuito, pero que con el uso continuado irán desarrollando cambios de hábitos y un apego emocional que les harán mucho más fácil plantearse cambiar de servicio. El objetivo es conseguir que muchos de los usuarios del servicio gratuito acaben suscribiéndose a la versión avanzada. Para lograr ese objetivo, la versión gratuita debe incluir un montón de elementos molestos (como, por ejemplo, anuncios) o carecer de algunas funciones clave (como la posibilidad de usar el servicio en determinados aparatos), que se eliminan o añaden según los casos en las versiones premium del servicio. El reto para Spotify y otros servicios freemium es conseguir equilibrar las diferentes versiones de modo que estimulen la conducta correcta en el consumidor y lo animen a convertirse en suscriptor de pago. Hasta la fecha, pocos servicios musicales han conseguido semejante proeza. O bien la versión gratuita era tan buena que no motivaba a los clientes a pasarse a un servicio de mayor calidad, o bien era tan deficiente que no atraía a nadie. (p. 435)

Para el caso de Spotify este modelo ha supuesto un crecimiento tanto en cantidad de usuarios totales como en usuarios que han pasado de tener una cuenta gratuita a una paga: mientras hace seis años sólo uno de cada cuatro era Premium, hoy la proporción ha crecido hasta casi uno de cada dos. En este sentido, según se puede leer en el Prospectus (el Registro de Declaración de 2018, presentado por la empresa ante la Comisión de Bolsa y Valores de Estados Unidos): "Nuestro Servicio con Publicidad sirve como un embudo, que genera más del 60\% de nuestros Suscriptores Premium agregados brutos totales desde que comenzamos a rastrear estos datos en febrero de 2014" (Spotify Technology S.A., 2018, p. 117). Por otra parte: "Nuestro Servicio Premium brinda a los Suscriptores Premium acceso ilimitado en línea y fuera de línea [online and offline] de alta calidad a nuestro catálogo" (p. 101). Y luego se agrega: "Además de acceder a nuestro catálogo en computadoras, tabletas y dispositivos móviles, los usuarios pueden conectarse a través de altavoces, receptores, televisores, automóviles, consolas de juegos y relojes inteligentes. El Servicio Premium ofrece una experiencia musical libre de publicidad” (p. 101).

El servicio alternativo sería, en relación con éste, más limitado: acceso sólo en línea a un catálogo disponible en menor calidad de audio, restringido al uso en un único dispositivo y con interrupciones publicitarias - las cuales, la mayoría de las veces, publicitan los beneficios que ofrece el servicio Premium-. Esto se debe -explica Vonderau (2017) - a que la propia Spotify ha señalado que "los anuncios tienen un doble propósito, generar un flujo de ingresos para la compañía, pero también incitar a los usuarios con aversión a la publicidad a pagar por Spotify 
Premium" (p. 9). Es parte de la lógica estratégica de embudo en un servicio freemium. A modo de ejemplo, tal como se puede escuchar cada seis o siete canciones en cualquier cuenta gratuita: "Consigue 30 días de Premium gratis. La música no para. Lo que paran son las publicidades. Prueba Premium. 30 días gratis”; o bien: “¿Qué es mejor que algo asombroso? Muchas cosas asombrosas en un solo paquete. Con Spotify Premium obtenés un montón de funciones increíbles: saltos ilimitados, modo offline, calidad de audio excepcional, conexión con casi cualquier dispositivo y canciones sin interrupciones. Presioná el banner para obtener más información". Asimismo, las publicidades y las ofertas también llegan por la vía del correo electrónico a quienes tengan una cuenta gratuita: "Es molesto cuando estás concentrado trabajando o estudiando y un ruido de la cocina te interrumpe, ¿no? Suscribiéndote a Spotify Premium los anuncios no interrumpen tu música ¡Probalo! Los primeros 3 meses son gratis. Escuchá lo que importa. Spotify Premium. Música sin anuncios y mucho más". Una lógica curiosamente semejante a la que nos enseña Hollywood sobre el proceder de las mafias: protegerte de ellos mismos.

Por otra parte, Arrese (2004) destaca la importancia de "la gestión de precios" de los productos culturales mediáticos, cuya finalidad sería la de "cubrir de forma rentable el coste del producto y ajustarse a las expectativas de valor de los clientes" (p. 12). Existen -sostiene"diferentes modalidades de fijación de precios de los medios, y por tanto de generación de ingresos", que "se concretan en distintos esquemas que compatibilizan gratuidad y pago -desde el punto de vista de los consumidores de contenidos-, condicionados por la financiación proveniente de terceros -fundamentalmente anunciantes y organismos públicos-" (p. 12). El hecho de que Spotify Argentina haya decidido, en 2018, mantener estable el precio de su servicio Premium durante los meses de corrida cambiaria y devaluación, disminuyendo así su recaudación en dólares, es un claro ejemplo de aquello que Arrese sintetiza como una extraordinaria flexibilidad en la política de precios de los productos culturales mediáticos, dado que sus características económicas (especialmente su estructura de costos y su intangibilidad), "unidas al hecho de que todos ellos compiten en una economía de la atención, plantean especiales retos a la fijación de precios" (2004, p. 12). El precio en este sector es, por tanto, "un elemento de gestión tremendamente dinámico, volátil, sujeto a infinidad de circunstancias de mercado, y de otro tipo, independientes del coste del producto" (Arrese, 2004, p. 12). En este sentido, el modelo de negocios freemium de Spotify podría ver mermar significativamente sus suscripciones de pago hacia suscripciones gratuitas en una coyuntura de contracción económica, en caso de no adaptarse oportunamente flexibilizando su precio. Asimismo, también se aplica una lógica de flexibilidad de precios en su "variedad de planes", tal como se puede leer en el Prospectus de 2018:

\begin{abstract}
Ofrecemos una variedad de planes de precios de suscripción para nuestro Servicio Premium, incluido nuestro plan estándar, el Plan familiar y el Plan de estudiantes, para atraer a los usuarios con diferentes estilos de vida y en diversos grupos demográficos y de edades. Nuestros precios varían según el plan y se adaptan a cada mercado local para alinearse con el poder adquisitivo del consumidor, los niveles de costos generales y la disposición a pagar por un servicio de música. (Spotify Technology S.A., 2018, p. 101)
\end{abstract}

Tanto la posibilidad de contar con suscripciones gratuitas (usuarios a los que se procurará seducir vía publicidad interna para pasarse al servicio pago) como el hecho de fijar precios flexibles (adaptables según demografía, edad o "estilos de vida") y relativamente bajos, supone 
aquella búsqueda empresaria que según Srnicek (2018) se resume en la fórmula "crecimiento primero, ganancias después” (p. 25). Esa búsqueda primera o primordial de crecimiento en volumen de usuarios es lo que, se supone, podrá posicionar a la empresa como una marca. Una vez más es Arrese (2004) quien nos dice que, en mercados "con demandas muy volátiles, cada vez tiene mayor importancia la creación de marcas fuertes (...), con una identidad consistente" (p. 15). Una vez consolidada, la empresa devenida marca podría redundar en una tendencia hacia la monopolización de la oferta. Y en efecto, si bien existen otras empresas-marca que ofrecen un servicio de streaming musical similar, Spotify se constituye en un mercado oligopólico con poca competencia y en el que parecería ser el mismo crecimiento de volumen de usuarios el que llama a más usuarios que redundan en mayor crecimiento. Esto es lo que Srnicek (2018) llama, como hecho característico de las plataformas digitales, el efecto de red: "mientras más numerosos sean los usuarios que hacen uso de una plataforma, más valiosa se vuelve esa plataforma para los demás (...). Más usuarios generan más usuarios, lo que lleva a que las plataformas tengan una tendencia natural a la monopolización" (p. 46-47). No es de extrañar, de esta suerte, que la marca destaque como elemento central entre sus "estrategias de crecimiento" el hecho de "mejorar continuamente nuestra plataforma para retener y hacer crecer nuestra base de usuarios" (Spotify Technology S.A., 2018, p. 104), puesto que, según afirman: "Nuestro negocio depende de una marca sólida, y cualquier falla en el mantenimiento, protección y mejora de nuestra marca afectaría nuestra capacidad de retener o expandir nuestra base de usuarios en el servicio con publicidad, suscriptores premium y anunciantes" (2018, p. 118).

\subsection{Crecimiento primero, ¿ganancias después?}

Ahora bien, crecer no es sinónimo de obtener beneficios netos. Y es que el problema histórico de Spotify ha sido precisamente que sus ingresos (publicidad y, principalmente, suscripciones), por más que altos y crecientes, siempre han sido menores a sus gastos fijos (personal, infraestructura, marketing, investigación y desarrollo, y fundamentalmente, regalías por derechos de autor), por lo que año a año los balances son negativos (ver Gráfico Nº4). "Entre el 80 y el 85 por ciento de lo que ingresa a la compañía vuelve a salir con dirección hacia los sellos y artistas", dice en una entrevista a la revista Rolling Stone el investigador sueco Pelle Snickars, uno de los autores de un reciente y crítico libro sobre Spotify (Wang, 2019). En este sentido, en la sección "Factores de riesgo. Riesgos relacionados con nuestro negocio", del Registro de Declaración de 2018, se declara que: "Hemos incurrido en pérdidas operativas significativas en el pasado, y es posible que no podamos generar ingresos suficientes para ser rentables, o generar un flujo de caja positivo de manera sostenida" (Spotify Technology S.A., 2018, p. 17). Y asimismo se lee: "Además, también esperamos que nuestros costos aumenten en períodos futuros, lo que podría afectar negativamente nuestros resultados operativos futuros y la capacidad de lograr rentabilidad" (p. 17). 
Gráfico n ${ }^{\circ}$ 4: Evolución de ingresos y pérdidas de Spotify (en millones de euros) (2009-2019)

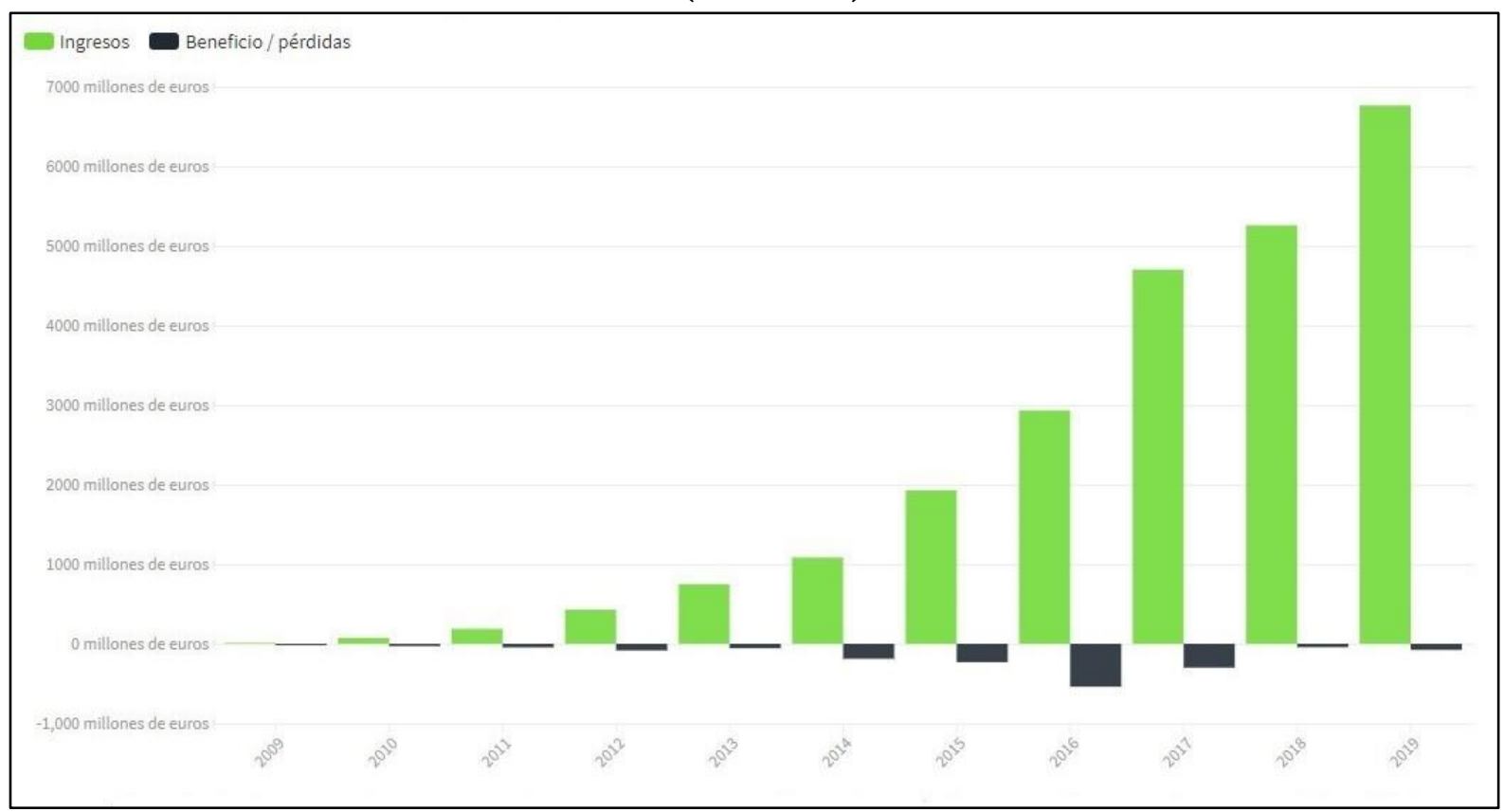

Fuente: García, 2020

A comienzos de la segunda década del nuevo siglo José María Álvarez Monzoncillo afirmaba que:

Las empresas digitales que aparecieron con Internet a mediados de los años noventa no encuentran modelos de negocio exitosos. Se pueden contar con los dedos de una mano a nivel internacional. Tienen facturaciones insignificantes en el conjunto del sector. No existe ningún new media importante en Internet (televisión, periódico, radio) que tenga un modelo de negocio rentable y asentado. Puede haber alguna fórmula que funcione, pero suele derivar del negocio tradicional. (Monzoncillo, 2011, p. 153)

Una década después de la publicación de estas líneas, la economía digital continúa ampliando sus fronteras, al punto de ser cada vez más los sectores que procuran acercarse y adaptarse a la dinámica de las plataformas. Sin embargo, Spotify se ajusta parcialmente a la definición de Monzoncillo: si bien no se trata de una empresa digital nacida a mediados de los años noventa sino surgida una larga década después (creada en 2006 se lanza al mercado en 20087), el éxito de su modelo de negocios aún está por verse, pues, jugando con las palabras de Monzoncillo, se diría que está asentado pero sin ser rentable. La apuesta por el modelo freemium se deja pensar por

\footnotetext{
7 Eriksson et al. (2019) explican ese lapso que va de la creación de 2006 a la comercialización desde 2008 como el período de pasaje desde la ilegalidad a la legalización. En efecto, los autores buscan poner en entredicho el mito de origen de la plataforma, según el cual la empresa habría nacido con el objetivo de devolver a la industria de la música al sendero de la legalidad subsanando las prácticas de piratería que la jaqueaban. Contrariamente al discurso del origen, una y otra vez repetido por las coberturas mediáticas y alimentado por la propia empresa, los autores muestran que durante aquellos largos y "oscuros" primeros meses Spotify funcionó como un servicio pirata que distribuía música sin licencia alguna, utilizando para ello The Pirate Bay y otras redes P2P. El lanzamiento de Spotify, concluyen los autores, "fue no el lanzamiento de un nuevo servicio sino el lanzamiento de un nuevo esfuerzo por monetizar un servicio ya existente” (p. 65).
} 
aquella otra frase de Monzoncillo (2011), según la cual -decía el autor en 2011- "al día de hoy, la red y la gratuidad es un tándem imposible de separar” (p. 153). A diez años de su publicación, la frase de Monzoncillo sigue siendo actual en la medida en que empresas digitales como Spotify se sostienen en el tiempo y crecen, pero siguen estando lejos de poder asegurar dividendos que la consoliden a largo plazo. "El gran reto -dice Monzoncillo- es buscar la monetización de los contenidos en Internet en un entorno que presiona hacia la gratuidad" (p. 155). Y prosigue: "Si [las empresas] no consiguen modelos mixtos de pago y gratuidad es muy difícil definir nuevos modelos de negocio en la red" (p. 159). Incluso, como hemos visto, con el modelo mixto establecido y en crecimiento en términos de posicionamiento de marca y cantidad de usuarios, los resultados económicos parecen estar lejos de cumplir las expectativas, puesto que, en más de una década desde que surgió comercialmente en 2008, fue el último trimestre de 2018 el que, por primera vez en su historia, arrojó un balance de números positivos para la compañía. Y hablamos de números trimestrales puesto que, tomado en su totalidad, 2018 dio pérdidas netas por $€ 43$ millones, 2019 llevó esas pérdidas a €186 millones, y 2020, de acuerdo con los balances financieros que -desde que comenzó a cotizar en bolsa en 2018- Spotify presenta anualmente en la Comisión de Bolsa y Valores de Estados Unidos, triplicó los números negativos a €581 millones. Quedará por demostrar si los beneficios netos se repetirán hacia adelante.

Por el momento la estrategia diseñada para tal fin incluye -además de la diversidad de planes de suscripción y los estímulos a las cuentas gratuitas para atraer nuevos usuarios de pago- reducir gastos (tarea difícil dado que los gastos fijos tienden a ser altos y el pago ineludible de regalías por derechos de autor representa el mayor egreso para la compañía); procurar "entrar en nuevas geografías" desembarcando y operando en nuevos países para escalar en usuarios activos (actualmente, según se especifica en el sitio web oficial, se encuentra disponible en 177 países distribuidos por los cinco continentes y se trata de un número que crece año a año); y por último pero no menos importante, ampliar el mercado de la oferta sonora hacia los podcasts, esto es, archivos digitales por lo general de audio que se asemejan parcialmente a un programa de radio, con uno o más locutores que suelen tratar alguna temática en particular, y con una publicación periódica de los contenidos que pueden ser escuchados -en diferido- en línea o bien descargados. En efecto, el nombre completo de Spotify en la App Store ahora contiene la palabra "podcasts" ("Spotify: música y podcasts") y el buscador de la aplicación invita a explorarlos, diversificando la oferta de contenidos que ya no será sólo musical:

\footnotetext{
Nuestra plataforma permite la diseminación de podcasts que cubren una amplia gama de géneros y temas, incluidos contenido musical, deportes, negocios y finanzas, viajes y cocina, entre muchos otros. Hubo un total de 348 millones de oyentes de podcasts en todas las plataformas en todo el mundo a fines de 2016 y el número de oyentes de podcast aumentó a un estimado de 484 millones en 2017 según Ovum, lo que representa un crecimiento del $39 \%$ de un año al otro. Este compromiso presenta una oportunidad significativa para Spotify, ya que creemos tenemos la capacidad de mejorar la experiencia del usuario del podcast con un mejor producto centrado en el descubrimiento. (Spotify Technology, 2018, p. 109)
}

Esta apuesta explica la compra reciente de dos compañías de plataforma especializadas una en la producción de podcasts y la otra en la facilitación de herramientas al gran público para su creación, distribución y publicación: Gimlet Media y Anchor, adquiridas por Spotify en 2019 - 
piénsese que, desde el punto de vista económico, si los usuarios utilizan la plataforma ya no sólo para escuchar música, sino podcasts, los ingresos de la empresa serán los mismos, pero el pago de regalías por derechos de autor será menor- (Rus, 2020). En el mismo sentido puede interpretarse la presentación -también en 2019 (y por el momento sólo)- para Estados Unidos, Australia y Suecia, de una nueva lista de reproducción, "Your Daily Drive" (Tu Viaje Diario): destinada a la escucha en automóvil y transporte público -aunque no exclusivamente-, se trata de una combinación de música y podcasts de noticias personalizados que se renuevan más de una vez por día, y cuya finalidad es ofrecer una alternativa a las estaciones de radio tradicionales ("con una oferta más robusta, más capacidades a pedido [on-demand] y acceso a listas de reproducción personalizadas, creemos que Spotify ofrece a los usuarios una alternativa significativamente mejor a la transmisión [broadcasting] lineal", se lee en el Prospectus), posicionándose de esta manera como una plataforma sonora todoterreno. De aquí que, en adelante, más preciso sería hablar de plataforma de streaming de audio, antes que (sólo) musical. Esta expansión podría hacer incluso, en el mediano plazo, que la referencia a la plataforma como "de audio" resulte asimismo insuficiente, como la propia empresa tecnológica se encarga de explicitar:

La música fue sólo el comienzo (...). Somos una plataforma de audio y hemos comenzado a expandirnos hacia contenido no-musical como podcasts. Esperamos expandir esta oferta con el tiempo para incluir otros contenidos que no sean de música, como palabras habladas y videos intersticiales cortos, [lo que ayudaría a proveer] una capa visual a nuestras ofertas de contenido $\left[\begin{array}{ll}y & a\end{array}\right]$ convertir a nuestros oyentes en espectadores de contenido. (Spotify Technology S.A., 2018, p. 105 y 110)

Esta cita pone de manifiesto, por un lado, que hay razones para pensar que Spotify no sería exactamente una empresa musical, sino que, más precisamente, y como sostienen Eriksson et al. (2019), existiría en la intersección de industrias, como la de la música, la publicidad, la tecnología y las finanzas. Por el otro, hace resonar una vez más la síntesis de la lógica de las plataformas digitales expresada por Srnicek: "crecimiento primero, ganancias después". Crecer y diversificarse para asentarse y posicionarse, en la búsqueda de generar las condiciones para una mayor concentración del mercado que redunde finalmente en el crecimiento que verdaderamente importa, el de la tasa de ganancia. Martín Becerra et al. (2013), en un trabajo sobre la concentración económica de los medios de comunicación, sostienen:

Los medios son instituciones complejas (...). A partir del tipo de mercancía con la que trabajan -que tiene doble valor, material y simbólico-, componen un actor particular y con consecuencias especiales a partir de sus acciones (...). Son un sector económico en el que la oferta define a la demanda y tienen altos costos fijos y bajos costos variables, es decir, que no hay incremento de los gastos cuando se logra crecimiento de las tasas de ganancia. Por todo esto, tienden a la concentración, organizan sus actividades con este formato, y van hacia la concentración en una deriva que puede generar barreras de ingreso a otros actores en el mercado. (Becerra et al., 2013, p. 107)

Si bien es cierto que los medios a los que se refieren aquí los autores son principalmente la prensa, la radio y la televisión, y aun cuando sería cuestionable o al menos problemático definir a las plataformas de streaming musical como medios de comunicación en el sentido que se les ha 
dado a estos medios a lo largo del siglo XX, no por ello deja de corroborarse, en el caso de Spotify, que efectivamente se tiende a una concentración que dificulta el ingreso de otros actores en el mercado, en la medida en que el robustecimiento de la oferta canaliza la demanda, lo que a su vez supone un aliciente para ampliar aún más la demanda (como vimos anteriormente, el efecto de red tiene una tendencia natural a la concentración y a la monopolización). Ahora bien, esta tendencia a la concentración del mercado de la escucha musical digital no ha producido hasta aquí una tendencia concomitante en el crecimiento sostenido de las tasas de ganancia. Por el contrario, la novedad mencionada relativa al saldo positivo en el último trimestre de 2018 demuestra la dificultad de hacer rentable un modelo de negocios que en el ámbito de los bienes (y servicios) simbólicos se presenta tan consolidado en el presente inmediato como incierto en el largo plazo. Y aunque Spotify se haya establecido como referencia insigne en el mundo de las plataformas de streaming musical, una marca fuerte con identidad consistente, por sí misma, no parece resultar suficiente.

Podría ser, como sugiere Srnicek (2018), que el modelo de "crecimiento primero, ganancias después" prescribe que tener pérdidas significativas es sólo parte de la estrategia. En tal caso quedará por demostrar, para la empresa, si será o no económicamente sostenible en el futuro. Srnicek plantea, para aquellas plataformas que se enfrentan a esta incertidumbre, dos opciones: "o bien cerrar el negocio o recortar los costos y subir los precios" (p. 110). Resulta difícil pensar, para casos como el de Spotify que se caracteriza por tener costos fijos altos, que pudiera hacer recortes significativos; de esta manera, si los balances por venir no consolidaran una continuidad de la rentabilidad en el tiempo, si la diversificación resultara insuficiente, y si no se decantara por la vía del cierre del negocio, quedaría esperar entonces una suba de precios en las suscripciones, algo que, por un lado, llevaría a reforzar las desigualdades en el acceso, y por otro, atentaría contra aquella flexibilidad en la política de precios de la que hablaba Arrese. En cualquier caso, quizás haríamos bien en recordar las palabras del músico Thom Yorke, quien dijo en una oportunidad: "Spotify es la última y desesperada flatulencia de un cadáver" (Ortelli, 2016).

Como sea, todo sucede como si, por encima de la base económica que no estaría aun en condiciones de sedimentar, la música de plataformas se asentara técnica y socioculturalmente. Es por ello que ahora, una vez analizada su lógica y dinámica económica, quedaría pendiente la pregunta por el modelo complementario, ya no el económico, sino el subjetivo: ¿Qué sujeto para qué escucha? Si las plataformas, como afirma Srnicek (2018), "tienen una arquitectura central establecida que controla las posibilidades de interacción” (p. 49), y si en su posición de intermediarias "ganan no sólo acceso a más datos, sino además control y gobierno sobre las reglas del juego" (p. 48), entonces ¿de qué tipo de control se trata y qué posibilidades de interacción se habilitan? ¿De qué manera se relaciona esto con los datos que se registran y qué tratamiento se hace de ellos y para qué? ¿Cuáles serían, finalmente, estas "reglas del juego", y cómo se configura qué subjetividad en ellas? Abordaremos estas preguntas en el siguiente apartado. 


\section{Modelo subjetivo: algoritmos de recomendación personalizada para el usuario (in)dividuado como perfil}

\subsection{Hacer cosas con la música: el contexto en el acceso al contenido}

Hemos visto, hasta aquí, que la lógica económica de las plataformas digitales puede llevar a la adopción de un modelo freemium que persigue la rentabilidad bajo una estrategia de "embudo", consistente en ofrecer como opción de rápido acceso una suscripción gratuita limitada en posibilidades de uso como puerta de entrada a un servicio de pago con mayores beneficios. Esta estrategia, económicamente incierta en el largo plazo, se muestra sin embargo sólida en términos de captación, retención y crecimiento de una base de usuarios que, por efectos de red, vuelve a la plataforma más atractiva para sumar nuevos usuarios y potenciales clientes al tiempo que consolida su nombre como una marca identitariamente consistente que procura afianzarse a través de la oferta de una "experiencia de usuario" distintiva y diferenciada. Ahora bien, por más que necesariamente relacionado con la economía, el diseño de la plataforma para la configuración de una determinada "experiencia de usuario" ya no forma parte del modelo de negocio. Se diría que, de modo complementario a éste, de lo que se trata en este punto es, precisamente, de la conformación de un modelo de usuario.

Patrik Wikström (2014) llama "servicio basado en contexto" al conjunto de elementos que otorgan a una plataforma sus rasgos más distintivos y específicos, aquello que, ya por fuera de la dinámica del intercambio y la posesión física del bien tradicional (como podía ser la típica compra de un disco compacto a finales del siglo XX), y una vez dentro del modelo del servicio digital y el acceso (acceso en primer lugar a internet, y luego a los contenidos disponibles en la plataforma), supone una serie de propiedades particulares relativas a las disposiciones y posibilidades de la interfaz con la que se interactúa: "El número de servicios basados en contexto no deja de crecer en paralelo a los servicios basados en acceso, y con bastante frecuencia los servicios musicales ya ofrecen acceso y, al mismo tiempo, toda una gama de funciones que permiten al usuario hacer cosas con la música" (Wikström, 2014, p. 440). El problema para el cliente que es necesario resolver, continúa Wikström, "no es cómo permitirle acceder a la música, sino cómo navegar y hacer cosas con esa música” (p. 440). Evidentemente, cuando el contenido es abundante, porque alcanza una cantidad de posibles que se cuenta en decenas de millones, es el contexto a través del cual se entra en relación con él el que lo vuelve realmente accesible. Este contexto tiene por una parte una modalidad visual, que consiste fundamentalmente en el despliegue de opciones de interacción que ofrece la plataforma al usuario como superficie(s) de navegación (página de inicio, barra de búsqueda, menú de opciones, hipervínculos, etc.), de acuerdo con un criterio de diseño (colores, tipografías, formas, tamaños, distribución espacial de texto e imagen, etc.) que puede o no variar en el tiempo. Pero además, detrás de las disposiciones visuales y por debajo de las interacciones de superficie, el contexto por el que se accede al contenido se define por lo que la plataforma hace con los datos con los que trabaja, y este hacer es invisible al consumo, por lo que habrá que rastrear su principio de funcionamiento, esto es, la lógica según la cual la plataforma organiza, clasifica, segmenta, jerarquiza y analiza la información que en cada interacción el usuario suministra, para devolverla y presentarla en forma de nuevas opciones de interacción.

De modo que la pregunta clave aquí se podría sintetizar de la siguiente manera: ¿Qué hace la plataforma con lo que el usuario hace de ella, teniendo en cuenta que el marco y las alternativas 
de acción de éste están en función de los parámetros que establece aquélla? Si bien todas las plataformas de streaming musical ofrecen actualmente un contexto de acceso a sus contenidos, por lo que sería posible, en este sentido, detectar algunos rasgos comunes entre ellas, se trata sin embargo de una pregunta que cada plataforma responderá individual y distintamente, pues el plus diferencial de cada una, aquello que se presenta y se promociona como la razón de su singularidad -y aquello que, presumiblemente, redundará en un mayor atractivo para un mayor crecimiento para una eventual rentabilidad-, es, precisamente, la particularidad de acuerdo con la cual se establece una propuesta de navegación y un "hacer cosas con la música" únicos. Por ello, siguiendo lo dispuesto en el apartado anterior, y por las mismas razones allí esgrimidas, circunscribiremos el análisis de las características de la plataforma, su tratamiento de los datos y el "sujeto modelo" que de ello se desprende a Spotify.

\subsection{El plus diferencial: personalización y descubrimiento}

En una carta de dos páginas que se incluye en el ya citado documento presentado ante la Comisión de Bolsa y Valores de Estados Unidos, el firmante Daniel Ek, cofundador y CEO de la compañía con sede en Suecia, se refiere implícitamente a la relación entre contenido y contexto, y explicita a grandes rasgos la política de singularización de la plataforma: "La paradoja central para los usuarios es que el acceso te da todo, pero todo no es suficiente. El descubrimiento es difícil sin una brújula. La elección sin precedentes a un precio asequible debe venir con una personalización efectiva para ayudar al público a navegar por un mar de contenido" (Spotify Technology, 2018, p. 91). El efecto de personalización se presenta así como una brújula para asistirnos en la navegación de los vastos contenidos y para orientarnos en el descubrimiento. Descubrimiento y personalización serán, en efecto, dos palabras claves en el desarrollo de esta política, como se puede observar en este otro fragmento: "Inicialmente, nuestras campañas fueron diseñadas para educar al mercado sobre el concepto de streaming de música a pedido y la funcionalidad de navegación que brindábamos" (Spotify Technology, 2018, p. 116). Pero: “A medida que la familiaridad con el modelo de acceso a la música se fue extendiendo, nuestros esfuerzos de promoción cambiaron para transmitir las capacidades de personalización y descubrimiento que habíamos desarrollado" (p. 116). El desarrollo de estas capacidades es lo que se pretende funcione como especificidad distintiva de la "experiencia de usuario" de la plataforma, lo que a su vez permitiría refrendar el modelo de negocios reforzando el crecimiento:

Creemos que nuestra superior Experiencia de Usuario es lo que ha permitido a Spotify convertirse en el servicio de suscripción de transmisión de música global más grande. Invertir en la experiencia del usuario ha generado y seguirá generando beneficios significativos para nuestra plataforma. A medida que nuestra personalización se vuelve más refinada y el descubrimiento de música se vuelve más fluido, creemos que aumentaremos el compromiso de nuestros usuarios actuales y atraeremos nuevos usuarios a nuestra plataforma. (Spotify Technology, 2018, p. 97)

Pero más allá de las campañas de promoción, de las declaraciones y declamaciones, ¿en qué consiste esta política del descubrimiento? (o habría que decir este "negocio" del descubrimiento, según los términos de la propia empresa: "Spotify es más que un servicio de streaming de música. Estamos en el negocio del descubrimiento"). ¿Qué es y cómo se vuelve más refinada esta personalización que reivindican? ¿Qué tipo de tratamiento de los datos se lleva a cabo para dar 
con ese plus diferencial que se persigue? Para responder estas preguntas será conveniente analizar el diseño de su sistema de recomendación, pues en él se condensa en buena medida la organización, clasificación, selección y jerarquización de aquello que se nos presenta en pantalla. Para ello, la siguiente cita funciona como un buen punto de partida, pues si bien se muestra imprecisa en cuanto a los números que revela (se trata de un texto de 2018), la encontramos no obstante exacta y actualizada en relación a la lógica de funcionamiento que trasunta, sintetizando de manera perfecta lo que caerá bajo el análisis del presente apartado:

Poseemos un conjunto de datos amplio y diversificado que nos proporciona información significativa sobre el consumo de contenido y el comportamiento del usuario. Al 31 de diciembre de 2017, este conjunto de datos es de más de 200 petabytes $[1$ petabyte $=1$ millón de gigabytes] (en comparación con 60 petabytes en Netflix a noviembre de 2016 según datos disponibles públicamente) y se consultan aproximadamente cinco petabytes por día (en comparación con aproximadamente tres petabytes consultados diariamente en Netflix, según datos disponibles públicamente a noviembre de 2016) (...). Dado que todos nuestros usuarios tienen que iniciar sesión para acceder a nuestro Servicio, esto nos permite rastrear comportamientos tales como reproducir canciones, compartir, seleccionar la música recomendada, omitir, seguir, y participar activamente a través de los botones de votación positiva y negativa. Más de 150 mil millones de este tipo de eventos se registran diariamente en nuestro Servicio. Además, dedicamos recursos sustanciales a analizar y manejar estos datos para obtener información útil con aprendizaje automático [machine learning] $\mathrm{e}$ inteligencia artificial (...). Tenemos la capacidad de personalizar y seleccionar el contenido que transmitimos midiendo las preferencias de un usuario individual con más de 40 parámetros diferentes. Nuestros algoritmos están diseñados para anticipar las preferencias de un usuario utilizando factores como la demografía y el comportamiento de escucha en el pasado. Además, podemos combinar el contexto situacional, como la hora del día y la ubicación, para hacer mejores recomendaciones de contenido apropiado a un usuario individual en función de su actividad actual. A medida que recopilamos y procesamos datos y comprendemos a nuestros usuarios, creemos que nuestra tecnología comprenderá y responderá mejor a sus preferencias, generará una experiencia de usuario aún mejor y diferenciará aún más nuestro Servicio de nuestros competidores. (Spotify Technology, 2018, p. 115)

Un sistema de recomendación funciona como un proceso de filtrado. Frente a una dinámica de acceso a un catálogo que se caracterizó siempre por su abundancia lindante con el exceso, y que cuenta en la actualidad con más de 70 millones de canciones y más de 4 mil millones de listas de reproducción (de acuerdo con cifras publicadas por la propia empresa), la búsqueda personal de música ${ }^{8}$ a seleccionar se complementa con una asistencia personalizada de sugerencias para la elección. Pero aunque presente desde sus inicios, la lógica de funcionamiento del sistema de

\footnotetext{
8 Spotify cuenta en la actualidad con más de 2,5 millones de títulos de podcasts. Si bien se encuentra desde fines de 2019 experimentando con un sistema de recomendación algorítmico similar al que implementa para recomendar canciones -llamado Your Daily Podcasts-, pero adaptando las instrucciones a un tipo de audio diferente, no lo tomaremos como parte del análisis, por tratarse de una creación reciente limitada a unos pocos países (por el momento Estados Unidos, Canadá, México, Brasil, Reino Unido, Alemania, Suecia, Australia y Nueva Zelanda) y en proceso de desarrollo. Para más información sobre el tema se puede visitar el sitio web oficial (donde se explicita, por ejemplo, cómo funciona el algoritmo de recomendación de podcasts): https://newsroom.spotify.com/2019-1119/your-daily-podcasts-playlist-makes-finding-your-next-favorite-show-easier-than-ever/
} 
recomendación de Spotify -la respuesta al problema de la "paradoja de elección", según la expresión de Anja Nylund Hagen” - no fue siempre la misma.

\subsection{El sistema de recomendación: de los inicios a la actualidad}

Podría decirse que durante los primeros años desde su lanzamiento la recomendación era un elemento secundario, pues se esperaba que el usuario navegara la interfaz siguiendo sus propias preferencias musicales; el eslogan de Spotify de aquel entonces así lo indicaba: Whatever You Want, Whenever You Want It (lo que tú quieras, cuando lo quieras). Se trataba, en efecto, de una lógica que concebía a la plataforma como prioritariamente on demand o "a pedido", y desde la que se construía un usuario modelo con un gusto musical fuerte y definido. Para el año 2011, como consecuencia de un acuerdo estratégico con Facebook, se buscó darle a la interfaz un aspecto más "social", que permitiera compartir en Facebook lo que se escuchara en Spotify; sobre este nuevo diseño el sistema de recomendación pasaba a estar basado en las canciones que los amigos virtuales del usuario seleccionaban para sus propias listas de reproducción -o playlists, según su nombre en inglés-, pero debido a la poca eficacia y a los consecuentes comentarios negativos esta estrategia fue pronto desestimada, y para 2013 ya se implementaba un nuevo enfoque. No obstante lo cual, más allá de la evolución del sistema de recomendación, la faceta social de la plataforma nunca estuvo desestimada, pudiendo los usuarios desde entonces y hasta la actualidad seguir a los músicos de su agrado y recibir notificaciones de próximos recitales, seguir y ser seguidos por otros usuarios, seguir y confeccionar listas de reproducción que otros podrán escuchar y a las que podrán suscribirse, y hacer públicas las escuchas en Facebook, Twitter, Telegram, Tumblr y Skype, procurando así establecer una "experiencia de usuario" más integral. Por otra parte, a mayor interacción entre plataformas, mayor y más diversa la recolección de los datos generados por el usuario.

Aquel nuevo enfoque estaba sostenido en los llamados "curadores expertos" de listas de reproducción, para lo cual compraron Tunigo, una compañía digital especializada en la recomendación humana de canciones y artistas agrupados por especialidad temática y estados de ánimo. A caballo de esta adquisición y de la apuesta por una nueva forma de recomendación musical Spotify fue actualizando sus eslóganes promocionales: Whatever You Want, Whenever You Want It fue reemplazado por Music For Every Moment (música para cada momento) y Soundtrack Your Life (algo así como: musicalizá tu vida, o hacé una banda sonora de tu vida), orientando de esta manera el sentido de la experiencia musical hacia una práctica situacional que toma en consideración el contexto de escucha: "Puedes crear la banda sonora de toda tu vida con Spotify. Lo que sea que estés haciendo o sintiendo, tenemos la música para hacerlo mejor”, se podía leer

\footnotetext{
${ }^{9}$ La investigadora noruega Anja Nylund Hagen (2015) sugiere que la sobreabundancia de oferta podría llevar a una "paradoja de elección", esto es, que la decisión sobre qué escuchar podría verse afectada por un catálogo percibido como inabarcable y resultar en una experiencia poco satisfactoria; pero - precisa la autora- no se trata realmente de un rechazo al fenómeno de la abundancia: cuando la paradoja de elección ocurre, el problema reside en la escasez de ayuda al momento de tomar la decisión.

10 Así expresa la compañía, en sus propios términos, su interés por la curaduría musical: "antes del lanzamiento en un nuevo mercado, generalmente optimizamos la experiencia local de Spotify para las preferencias musicales locales. Un usuario en los Estados Unidos generalmente tiene preferencias muy diferentes que un usuario en México, Japón o Suecia. Buscamos obtener los derechos sobre el contenido popular local y tener curadores locales donde tenga sentido (...). Nuestro equipo editorial selecciona cuidadosamente las listas de reproducción que permiten a los usuarios escuchar música en géneros específicos o que coincidan con sus estados de ánimo" (Spotify Technology, 2018, p. 105).
} 
en la página web de la plataforma en aquellos años, tiempo en que la compañía comenzaba a agregar una clara valoración afectiva en la interpelación al usuario. Es en este momento que aparecen las múltiples listas de reproducción asociadas a la categoría Géneros y estados de ánimo, al interior de la cual se despliegan un abanico de opciones que a su vez contienen otras tantas playlists, tales como (y la lista no tiene desperdicio):

En casa (descripta como "Ponle banda sonora a tu casa", y subdividida en "Buen Día: ¡Una inyección de alegría para tus mañanas!”; "Mates y Música: música para acompañar esas rondas interminables de mates"; “Té Para Tres: música ideal para tomar el té y relajar”, etc.); Cocinar (subdividida en "Cena con Amigos: la banda sonora para tus cenas en casa"; "Relax Brunch: beats que le suben el ánimo a tu día”; etc.); Para dormir (subdividida en "Sueño Profundo: música ambiental para un sueño profundo"; "Siesta Acústica: guitarras relajantes para descansar y recuperar fuerzas", etc.); Concentración (subdividida en "Impulso Creativo: bases suaves para inspirarte mientras trabajas"; "Música para leer: una bella banda sonora que acompañará tu tiempo de lectura"; "Música para Pintar: todo lucirá más hermoso si te inspiras con música instrumental"; "En el Trabajo: música alegre para que el trabajo se te pase volando"; etc.); Relax (subdividida en "Vibra Tropical: ¡Dale buena onda cálida y frutal a tu día!”; "Momento acústico: temas tranqui para cualquier momento del día"; "Hora del Drink: un merecido momento de relajación para el fin de la jornada"; etc.); Viajes (subdividida en "Canta en el Auto: canciones para subirse al auto y cantar sin parar"; "De Camino: una buena mezcla animada para acompañarte en tu trayecto"; "Directo a Clase: ¡Es temprano, pero iniciamos con toda la energía!"; etc.); más recientemente Bienestar (subdividida en "Amanecer con Yoga: el soundtrack ideal para tu sesión matutina"; "Antiestrés: relájate y toma un profundo respiro de serenidad auditiva"; "Maldita Hamburguesa: música motivacional para quemar esa hamburguesa que comiste el finde"), y un largo etcétera orientado en la misma dirección: aquella que pone en relación una canción con un estado de ánimo y/o una actividad.

Según Asher T. Chodos (2019), así concebida en términos de soundtrack, la música se presenta como en función de otra cosa, haciendo las veces de condimento (como la sal) o de aderezo (como la mayonesa), operando como un agregado secundario que se vuelve vital para sazonar un momento, actividad o estado anímico -concepción de la que se podría desprender que, al igual que la sal y la mayonesa, la música no es buena por sí sola-. Por otra parte, de acuerdo con Eriksson et al. (2019), este particular modo de interpelación -tal como aparece en las listas de reproducción mencionadas- comprendería la construcción de una particular noción de la temporalidad, ligada a "prescripciones crono-normativas de 'la buena vida' que instruyen a los usuarios a levantarse de la cama, ir a trabajar (en una oficina), hacer ejercicio por la tarde y luego socializar con amigos, familiares y amantes por la noche" (p. 167). De este modo, "la música se presenta como una forma de aumentar la productividad y el rendimiento en estas actividades de duración determinada" (Eriksson et al., 2019, p. 167). Puede observarse así la manera en que Spotify apela a una positividad psicológica, incentivada en la descripción valorativa de cada categoría (inyección de alegría, relajar, recuperar fuerzas, buena onda, toda la energía, música motivacional, etc.) y acompañada con cada lista de reproducción: una compañía musical para mantener un determinado estado emocional (valorado como positivo, productivo, óptimo, optimista) o bien para acceder a él. Se podría decir, hasta aquí, que la recomendación musical es afectiva y contextualizada, en tanto interpela a un sujeto-usuario situado cuya escucha se da en el cruce entre sus actividades y sus emociones. Pero hay más. 
En 2015, Daniel Ek, CEO y rostro visible de la empresa, había dicho que "la música se está alejando de los géneros" (Eriksson et al., 2019). ¿Y hacia dónde se dirigía? En Spotify, hacia la personalización: del momento, adaptando la escucha al contexto y orientándola cual brújula anímico-afectiva. Un ejemplo de ello fue la presentación de Spotify Running, una función que utilizaba los sensores del smartphone para detectar el ritmo del corredor y reproducir música a la misma velocidad. Un año antes, en 2014, Spotify compraba The Echo Nest y volvía a dar un giro a su sistema de recomendación, inaugurando una nueva zona de exploración y descubrimiento, con una nueva lista de reproducción como nuevo estandarte: Discover Weekly ("Tu descubrimiento semanal"), ya no de base social, tampoco curatorial humana, sino algorítmica. Este nuevo enfoque, que desde entonces se convirtió en un éxito entre los usuarios y en una característica distintiva de la "experiencia de escucha" ofrecida, habilita y promueve una mayor comunicación humano-máquina, en el sentido cibernético del término, como se verá a continuación.

\title{
3.4. En el corazón de Spotify: el Machine Learning y los modelos algorítmicos
}

En una nota publicada por el sitio web oficial en enero de 2020, firmada por la "Ingeniería de Spotify" y titulada "Sólo para tus oídos: personalizando Spotify Home con Machine Learning", se puede leer lo que sigue:

\begin{abstract}
El aprendizaje automático [macbine learning] está en el corazón de todo lo que hacemos en Spotify. Especialmente en Spotify Home [página de inicio de la plataforma], donde nos permite personalizar la experiencia del usuario y brindar a miles de millones de fanáticos la oportunidad de disfrutar e inspirarse en los artistas de nuestra plataforma. Esto es lo que hace que Spotify sea único (...). Podemos crear este nivel de personalización en tiempo real para nuestros 248 millones de usuarios activos mensuales, combinando el poder del aprendizaje automático con su historial de escucha, elecciones musicales, duración de la escucha y voluntad de actuar según las recomendaciones. Nos gusta decir que no hay "un" Spotify verdadero. Esencialmente, hay 248 millones de versiones del producto, juna para cada usuario! (Spotify Labs, 2020)
\end{abstract}

El Aprendizaje Automático (también llamado Aprendizaje de las Máquinas), conocido por su nombre en inglés como Machine Learning, es un desprendimiento de la Inteligencia Artificial -ésta a su vez una rama de la Cibernética-, y si bien fue acuñado en 1959 por Arthur Samuel (quien lo definió como el "campo de estudio que da a las computadoras la capacidad de aprender sin ser explícitamente programadas"), empezó a ser estudiado como un campo separado en la década de 1990 (Portugal et al., 2018, p. 4). De acuerdo con estos autores, el "Machine Learning utiliza computadoras para simular el aprendizaje humano y permite a las computadoras identificar y adquirir conocimiento del mundo real, así como mejorar el rendimiento en algunas tareas basadas en este nuevo conocimiento" (Portugal et al., 2018, p. 4). Es decir que el Machine Learning permite a un sistema aprender de los datos más allá de su programación. Básicamente se trata del uso de algoritmos para la creación de modelos de análisis de datos que utilizan los resultados del análisis como nuevos datos de entrada, los cuales volverán a ser procesados en un nuevo análisis, generando una espiral de retroalimentación (feedback) que permite incrementar los niveles de precisión en la resolución de algún tipo de problema, con la finalidad de "predecir el gusto de los consumidores y las reglas que están detrás de su comportamiento" (Arcila-Calderón 
et al., 2019, p. 649). Si la recomendación de una canción, por caso, es escuchada y marcada como favorita, la máquina algorítmica de la plataforma "interpretará" como un acierto la recomendación, sirviendo este hecho (o "evento") como nuevo dato de entrada que servirá de reforzamiento para orientar la recomendación siguiente; si la canción recomendada, por el contrario, es escuchada unos pocos segundos y salteada, esto también configurará un nuevo dato de entrada, que será "evaluado" por el sistema de recomendación para reorientar la recomendación siguiente, a la manera en que el GPS "recalcula" un nuevo recorrido cuando se hace caso omiso de sus indicaciones. La posibilidad predictiva del algoritmo, de esta suerte, estaría en función de los niveles de precisión alcanzados por el sistema de recomendación, lo que a su vez estaría en función de la cantidad de datos de los que se disponga para su análisis: a mayor masa de datos producida por la interacción del usuario con la plataforma, mayores las posibilidades de calibrar las recomendaciones -por efecto de retroalimentación-, lo que a su vez redunda en una mayor probabilidad de anticipar algorítmicamente sus gustos o preferencias, cuyo resultado sería la progresiva optimización de la personalización (de la recomendación).

Concretamente, el Machine Learning que habita en el "corazón” de Spotify -según la expresión utilizada por los propios ingenieros informáticos de la plataforma- se sirve de tres modelos algorítmicos para la puesta en marcha de su sistema de recomendación: el "modelo basado en contenido", el "modelo de filtrado colaborativo" y el "modelo de procesamiento del lenguaje natural". De manera general, un modelo basado en contenidos genera recomendaciones basándose en dos fuentes de información: "las características asociadas a los items [canciones, películas, electrodomésticos, etc.] y los ratings [valoraciones] que los usuarios han dado a dichos ítems. Recomiendan ítems cuyas características son similares a las de otros ítems que han sido valorados positivamente en el pasado" (Yepes Vélez et al., 2019, p. 41). Un modelo de filtrado colaborativo genera recomendaciones usando sólo la información existente de los perfiles de los diferentes usuarios: "En su forma más simple, recomiendan al usuario activo los ítems que otros usuarios con gustos similares han valorado de forma positiva en el pasado. La similitud de unos usuarios con otros es calculada en base a la similitud de los ratings dados por ambos usuarios a los mismos ítems en el pasado" (Yepes Vélez et al., 2019, p. 41). Dicho con otras palabras, este modelo algorítmico parte de una premisa simple, según la cual los usuarios que comparten algunas preferencias también compartirán otras (Lury y Day, 2019). Se llama Procesamiento del Lenguaje Natural, por último, a la recuperación, procesamiento y análisis computacional que se hace de la expresión lingüística humana (sea ésta escrita u oral). Suele ser utilizado para rastrear en la Web la valoración dispersa en forma de opiniones que se tiene de un tema en particular y, como sugiere Sanjinés Flores (2019), es ampliamente implementado en lo que se denomina "minería de opiniones" (que es un subproducto de la minería de datos):

La Minería de Opiniones o también llamado Análisis de Sentimiento, permite el procesamiento y la extracción automática de información clasificándola como opinión positiva, negativa o neutral, considerando que la información en muchas ocasiones se encuentra de forma no estructurada y es subjetiva debido a que maneja un lenguaje natural. (p. 98)

De este modo, un modelo de procesamiento del lenguaje natural genera recomendaciones a partir de la puesta en relación de la información registrada del usuario relativa a ítems valorados positivamente con opiniones (información textual que se encuentra en la Web en blogs, noticias, 
foros, etc.) que valoran positivamente esos ítems y otros similares, los cuales serán "interpretados" como de valor para el usuario y por lo tanto recomendados. Veamos cómo funcionan estos modelos en la plataforma.

Discover Weekly es hoy la propuesta más desarrollada por Spotify para la personalización musical. Se trata de una playlist de 30 canciones actualizadas una vez por semana y hecha a medida para cada usuario de acuerdo a sus gustos plasmados en sus escuchas anteriores. No por casualidad, decíamos más arriba, la incorporación de esta propuesta se remonta a 2015, año posterior a la compra de The Echo Nest, una start-up dedicada al almacenamiento y tratamiento de todo tipo de datos musicales que potenció las capacidades analíticas de la base de datos de la compañía de origen sueco. En un estudio comparativo sobre el funcionamiento algorítmico en las plataformas de streaming musical, Robert Prey (2018) destaca la singularidad de The Echo Nest en el tratamiento de los datos; allí se puede leer, en palabras del cofundador de la empresa, cómo el programa utilizado para el análisis musical algorítmico funcionaría de la siguiente manera: "El sistema ingiere y analiza el MP3, tratando de comprender cada pequeño evento de la canción, como una nota en un solo de guitarra o la manera en que dos notas están conectadas. Una canción promedio tiene unos dos mil de estos 'eventos' para que el sistema analice. Luego hace conexiones entre esa canción y otra canción con progresiones o estructuras similares" (citado en Prey, 2018, p. 1090). El programa lleva a cabo clasificaciones y asociaciones basadas en múltiples factores sonoros tales como la frecuencia, el tempo, la métrica, la tonalidad, el timbre de la voz, el volumen, el nivel de distorsión, etc.; de aquí que la sugerencia de escucha se establezca a partir de la detección automática de afinidades entre algunos de estos "eventos" diseminados por el catálogo de la plataforma y aquellos otros que forman parte de las canciones del gusto del usuario. Se le llama "modelo basado en contenido" porque clasifica y establece relaciones a partir del análisis de las propiedades acústicas intrínsecas de cada pista de audio.

Pero hay, para Prey, una segunda característica central en la analítica musical algorítmica de The Echo Nest: no sólo cuantifica sonidos, también recoge y analiza textos y conversaciones online sobre música que tienen lugar en blogs, sitios de crítica musical y redes sociales, de todo el mundo y en cualquier momento. En esta oportunidad se pasa el tamiz por las descripciones y reseñas online de las canciones y artistas escuchados y se compilan frases y palabras clave que luego son relacionadas con frases y palabras claves similares de otras canciones y artistas; su finalidad es, por un lado, la de relacionar una canción a una serie de significados sociales dispersos por la Web relativos a esa canción, y al mismo tiempo, asociar esa significación a otras canciones identificadas como similares. Este proceso supone la utilización de lo que, como adelantamos más arriba, se conoce como Procesamiento del Lenguaje Natural, modelo algorítmico que facilita el tratamiento automático de la documentación textual destinado al análisis de la información semántica producida por seres humanos de forma escrita (como en el caso de The Echo Nest) u oral. De esta manera, si a un usuario le gusta la banda X, y esa banda es descrita en distintas publicaciones digitales con la adjetivación $\mathrm{Y}$, entonces se le podrán recomendar canciones de bandas de las que se sepa (es decir, de aquellas cuyos datos semánticos hayan sido almacenados y analizados) que hayan sido adjetivadas de igual o similar modo en otras publicaciones digitales; o bien se le podrán recomendar canciones de la banda $\mathrm{Z}$ por haber sido asociada a $\mathrm{X}$ en alguna otra publicación.

Debido a la diversidad de procedimientos algorítmicos utilizados para efectuar las sugerencias se puede decir que el de Spotify es un sistema de recomendación híbrido (Portugal et al., 2018, p. 3; Yepes Vélez et al., 2019, p. 41). Los dos mecanismos de recomendación personalizada 
mencionados en el párrafo anterior, utilizados desde la adquisición de The Echo Nest y llamados respectivamente "modelo basado en contenido" y "modelo de procesamiento del lenguaje natural", se complementan con un tercero: el "modelo de filtrado colaborativo"11. Por distintas razones tanto el modelo basado en contenido como el de filtrado colaborativo podrían sintetizarse en la fórmula Si te gustó X también te gustará $Y$. En el primer caso, como vimos, la Y se convierte en objeto de recomendación al detectarse similitudes sonoras con la X que fue de mi escucha y gusto previos. En el caso del modelo de filtrado colaborativo, la X representaría una canción indicada como favorita, o guardada como parte de la confección de una lista de reproducción, o escuchada muchas veces, mientras $\mathrm{Y}$ sería la recomendación basada en otros usuarios a los que habiéndoles gustado $\mathrm{X}$ también les gustó $\mathrm{Y}$. Dicho con otras palabras: si mis preferencias musicales se asemejan a las preferencias musicales de otros usuarios, si se supone que me gusta la canción $\mathrm{A}, \mathrm{B}$ y $\mathrm{C}$, y a otro usuario le gustan $\mathrm{A}, \mathrm{B}$ y $\mathrm{D}$, entonces a mí se me recomendará $\mathrm{D}, \mathrm{y}$ al otro, $\mathrm{C}$. Una fórmula alternativa que también resumiría este procedimiento sería: A usuarios como vos les gustaron cosas como éstas. Y en efecto, la plataforma incluye una opción exploratoria llamada Fans Also Like ("A los admiradores también les gusta"), cuyo procedimiento algorítmico trabaja tanto con el modelo de filtrado colaborativo como con el modelo de procesamiento del lenguaje natural, pues de acuerdo con las palabras de Glenn McDonald, el así presentado por el sitio Web- "alquimista de datos de Spotify", se basa principalmente en dos factores:

El primero es admiradores [fans] compartidos, particularmente entre los artistas que podrían existir en los márgenes. Cuantos más admiradores tengan en común dos artistas, y cuanto mayor sea la proporción del total de admiradores de cada artista que representan los admiradores compartidos, más similares los consideramos. Si una banda aspirante tiene 10,000 admiradores, y 6,000 de ellos también son admiradores de otra banda que también tiene 10,000 admiradores, es una buena señal de que las dos bandas son probablemente similares (...). El segundo [factor] involucra descripciones compartidas, usando no solo el contenido en Spotify sino también en blogs, revistas y en otros lugares donde se discute de música. Analizamos páginas web sobre música todos los días y combinamos esa información con varias otras fuentes de descripciones de artistas, y luego buscamos patrones en el vocabulario descriptivo compartido. Cuanto más específico sea un descriptor, mayor será la probabilidad de que se produzca una coincidencia entre los artistas que lo comparten. Si dos artistas se describen con frecuencia como 'pop', eso no es tan interesante, porque muchos artistas se describen como 'pop'. Si dos artistas son frecuentemente descritos como 'polka metal', eso es mucho más inusual y, por lo tanto, una señal mucho mejor de que las dos bandas podrían ser similares. (Spotify for Artists, 2019)

Retomando la lista semanal de canciones de Discover Weekly, entonces y finalmente, parte del proceso de confección automática se construye vía filtrado colaborativo a partir de las propias selecciones de canciones y artistas que alimentan la base de datos de la plataforma, que serán primero rastreados algorítmicamente en las proliferantes playlists hechas tanto por otros usuarios como por la propia Spotify, para luego identificar en ellas aquellas canciones que no

${ }^{11}$ Lo que no se sabe, más allá de la identificación y descripción del funcionamiento de los tres modelos algorítmicos de los que se sirve el machine learning de Spotify, es cómo una lista de reproducción es concretamente curada: en qué proporciones y de acuerdo a qué criterios se recurre a cada uno de los modelos en cada recomendación. Eso es, para Spotify, un secreto comercial cuidadosamente guardado. 
hemos escuchado, y finalmente filtrar aquellas que el algoritmo reconoce como compatibles con el perfil musical que construye del usuario. El resultado es el descubrimiento semanal de canciones que no conocemos (al menos, que nunca hemos escuchado en Spotify) y que son para nosotros (al menos, que se ajustan al perfil musical que nuestros datos interactivos y retroactivos alimentan). Cabe destacar que para fortalecer las recomendaciones basadas en las escuchas de otros usuarios Spotify compra, en 2016, Soundwave, una aplicación que funcionaba como red social con la que ya existía previamente un acuerdo, pues en ella se podía seguir y ser seguido por otras personas, de las que era posible conocer su historial de canciones escuchadas en Spotify, indicar en cada caso si gustaban o disgustaban, marcarlas como favoritas y compartirlas con los propios seguidores de la app o bien a través de Facebook, todo lo cual operaba como datos algorítmicamente procesados que servían para obtener recomendaciones procedentes de los cruces de las escuchas propias con las que gustaran de las listas de los usuarios seguidos.

Con posterioridad a la posibilidad del descubrimiento semanal, Spotify incorporó el "descubrimiento diario" a las listas Made For You ("Especialmente para tí"), cuatro playlists potencialmente interminables en tanto se van agregando canciones a medida que se continúa escuchando, una selección automática basada en las últimas escuchas y en el perfil de gusto del usuario. Your Daily Mix, tal el nombre en inglés de estas listas de reproducción, propone "escuchar la música que amás sin esfuerzo", porque si todo descubrimiento consume tiempo y dedicación, Spotify ofrece eliminar el proceso para dar directamente con el resultado, un descubrimiento automático que vendría a filtrar, en nuestro beneficio, la trabajosa búsqueda de todo acontecimiento musical. La misma tesitura discursiva se observa en Releases Radar ("Tu radar de novedades"), otra oferta de playlist personalizada, esta vez destinada a los nuevos lanzamientos semanales que se ajustarían a cada perfil musical. Por otra parte, también la función de radio se personaliza, en la oferta disponible -para cada elección de escucha- de "Ir a radio de la canción" o "Ir a radio del artista": "además de nuestras miles de listas de reproducción, ofrecemos un servicio de transmisión de radio inteligente y sensible, que crece y evoluciona junto con el gusto y las elecciones de los usuarios" (Spotify Technology, 2018, p. 108), se lee en el Prospectus. Y concluye: "Nuestra función de radio utiliza algoritmos que toman la canción o el artista elegido por el usuario para crear una estación de radio en línea" (p. 108). Políticas algorítmicas de asistencias y delegaciones, exclusivamente para mí.

Pero como buen hijo de su tiempo, Spotify también sabe que las heterogeneidades identitarias y las exploraciones culturales son parte necesaria de un perfil subjetivo que se precie, por lo que no conforme con las recomendaciones personalizadas algorítmicamente inferidas como apropiadas y justas para mi gusto, la plataforma presenta una suerte de lado $B$, o más precisamente, "Tu Cara B", una lista de reproducción para "ampliar tus horizontes musicales": Tastebreakers (según su nombre en inglés), una playlist "rompe-gustos" con canciones de géneros y artistas "que no sueles escuchar y que seguro que te encantan". Canciones que probablemente me gusten pero o bien todavía no lo sé o bien lo he olvidado. Y si se trata de contrarrestar el olvido, Forgotiff ${ }^{12}$ es una aplicación y sitio web desarrollados para seleccionar al azar entre aquellas millones de canciones que nunca han sido escuchadas en la plataforma, a la vez que una apuesta exploratoria alternativa ${ }^{13}$.

\footnotetext{
12 Neologismo formado por la combinación de las palabras forgotten - “olvidado” en inglés- y Spotify.

13 "Millones de canciones en Spotify han sido olvidadas. Vamos a darles una nueva vida en nuevos oídos: los tuyos", se lee en el sitio web. "Amamos la música. Por eso nos sorprendió tanto saber que millones de canciones de Spotify se habían reproducido sólo parcialmente o nunca. Una parodia musical, realmente. Así que nos propusimos dar a
} 


\title{
3.5. El perfil: ese doble digital móvil y dividual
}

Pues bien, desde la perspectiva de la compañía, éstas serían las palabras que resumen el detrás de escena (o de pantalla) de la plataforma:

\begin{abstract}
Combinamos una interfaz de usuario elegante y sin problemas con nuestras capacidades de inteligencia artificial y aprendizaje automático para crear una plataforma sofisticada pero fácil de usar [user-friendly]. Desde el momento en que los usuarios abren la aplicación Spotify, les servimos una página de inicio personalizada con contenido que refleja nuestra comprensión de sus gustos musicales, hábitos de escucha pasados, estados de ánimo musicales y actividades diarias (...). Nuestra capacidad de aprovechar nuestros datos nos permite conocer a nuestros usuarios. Creemos que entendemos a las personas a través de la música, su estado de ánimo, mentalidad, actividades y gustos". (Spotify Technology S.A., 2018, p. 105 y 113)
\end{abstract}

Así pues, de un lado, se puede percibir aquello que Eriksson et al. (2019) definen como el deseo aparente de Spotify de automatizar y dejar que las máquinas algorítmicas se hagan cargo del manejo de la plataforma, hecho apreciable en declaraciones como la precedente, pero también en la fórmula que se promueve desde el departamento de Machine Learning de la empresa: "music + math = epic" (música + matemática = épica) (Eriksson et al., 2019), y por supuesto, en adquisiciones de start-ups dedicadas a la curación algorítmica de contenidos musicales, como la estadounidense The Echo Nest y la irlandesa Soundwave, a las que se pueden sumar la inglesa Sonalytic en 2017 (empresa digital dedicada a la detección automática de características de audio, cuya compra apunta a la profundización del análisis algorítmico de los "pequeños eventos musicales" detallados más arriba) y la francesa Niland, adquirida también en 2017 (empresa que aplica la inteligencia artificial para una recomendación personalizada basada en el análisis de canciones cuyas similitudes son clasificadas y segmentadas en géneros). Del otro lado, en relación a la capacidad de aprovechar los datos para conocer y entender a las personas, se deja ver cómo la aplicación de la plataforma -es decir su uso mediante dispositivo móvilpermite el ingreso, almacenamiento y análisis de otra serie de datos complementarios cuya función es la de contextualizar el comportamiento musical del usuario, de manera que al carácter híbrido del sistema de recomendación se le suma un filtro más. "Un contexto -dicen Portugal et al. - es un conjunto de información sobre el estado actual del usuario, como la hora en la ubicación del usuario (mañana, tarde, noche) o su actividad (inactivo, corriendo, durmiendo)" (2018, p. 3). La app en el teléfono celular recoge datos de localización geográfica, movimiento y actividad, momento del día en que se escucha música, señales espacio-temporales que son procesadas por aquello que desde el campo de los algorithmic studies se ha dado en llamar los "algoritmos sensibles al contexto" (Pichl, Zangerle y Specht, 2015) y cuya finalidad es la de situar los comportamientos musicales para dar con una recomendación ajustada al aqui y ahora del usuario.

estas canciones olvidadas otra forma de llegar a tus orificios auditivos". Para más información ver: https://forgotify.com/ 
Los datos de entrada (suministrados por el usuario) se procesan algorítmicamente para obtener datos de salida (suministrados para el usuario), sobre los cuales el usuario a su vez (re)accionará, generando nuevos datos de entrada. Toda la batería filtros y brújulas, es decir, de recomendaciones automáticas personalizadas y retroalimentadas, es así remitida a un sujeto destinatario que se individúa entonces como perfil ¿Pero qué es exactamente este individuo-perfil? Pablo Rodríguez (2018) lo define como "la serie de datos asignados a un sujeto en la vida social digital" (p. 20), y puesto que la vida social se desenvuelve cotidianamente en un sinfín de actividades digitales, "los perfiles se transforman en espacios privilegiados para la constitución misma de las identidades" (p. 21). Se diría que el perfil es la línea que dibuja algorítmicamente el conjunto de los datos que producen las prácticas en línea (online) del sujeto-conectado (otra manera de decir del usuario). En el caso de Spotify esta línea perfila el gusto musical, un hábito de escucha que se procesa como datos de conducta y que se va trazando en cada interacción. El perfil musical se completa con un perfil anímico derivado, o habría que decir, más precisamente, que el perfil musical es concebido asimismo como un perfil anímico, esto es, que del gusto delineado (por la elección de canciones y artistas, las destacadas como favoritas y las que se saltean, el lugar y momento en que se seleccionan, la actividad que acompaña la escucha, etc.) se desprende o se infiere un cierto estado afectivo-emotivo -afectividad calculable, vale decir, o cálculo de afectividad, en la medida en que resulta de un análisis computacional de datos-.

Cabe destacar que este perfil, construido sobre el análisis de micro-comportamientos, no sólo nutrirá la base de datos para la optimización de la personalización de la recomendación musical, sino que también, se presume, será de utilidad para las micro-segmentaciones de mercado desde las que los anunciantes diseñarán a medida el mensaje publicitario personalizado de sus productos. Si bien la suscripción Premium de Spotify se diferencia de la suscripción Free-como vimos- por el hecho de no incluir interrupciones publicitarias entre canciones, las listas de reproducción en la versión paga de la plataforma pueden estar esponsoreadas por marcas y productos. Cuanto mayor sea el almacenamiento de datos (musicales, contextuales y emocionales), mayores serán las posibilidades de precisión del análisis; y a mayor precisión analítica, mayor probabilidad de eficacia predictiva en la recomendación directa de música e indirecta de marcas y productos. De allí que se pueda observar a la marca de bebidas Gatorade esponsoreando listas de reproducción de "música para hacer ejercicio" (Workout Music), o a Bacardi en listas de "música de fiesta" (Party Music) (Prey, 2018). Y de allí que, al decir de Eriksson et al. (2019), Spotify no actúe sólo ni principalmente como un proveedor de música, o de audio, sino como un accionista privado de datos que "ha promovido abiertamente su colección masiva de datos contextuales como un servicio para los anunciantes" (p. 4), por lo cual -concluyen- "la música se ha convertido en datos, y los datos se han convertido en material contextual para la perfilización del usuario a escala” (p. 5). Así las cosas, insisten los autores, habría que pensar a Spotify menos como un intermediario que conecta individuos con archivos sonoros y más como un "mediador", en el sentido que este término tiene para Bruno Latour, esto es, "como un actor que transforma, traduce y modifica el sentido de los elementos que se supone debe transportar" (p. 15). De modo que estaríamos en condiciones de decir, en este punto, que si las plataformas digitales son constructos tecno-económicos mediados por las actividades de los usuarios (tal como las definíamos al comienzo del artículo siguiendo a Eriksson et al.), es preciso captar también el carácter político implicado en esas actividades, así como en el diseño y la configuración de los parámetros con relación a los cuales dichas actividades tienen lugar. Así, a las relaciones entre economía, técnica y subjetividad (o entre mercado, tecnologías 
computacionales y usuarios, si recordamos la definición de plataformas digitales de Eriksson et al.) corresponde entonces añadir un cuarto componente: el poder -temática que sin embargo excede el propósito de estas páginas-.

Podría decirse que si los medios de comunicación tradicionales del siglo XX entraban en relación con las masas, a las que estaban dirigidos, las plataformas digitales actuales entran en relación con estos individuos de los que se traza su perfil. El pasaje implica una transformación en la idea y puesta en forma del destinatario, que ya no será concebido como una generalidad más o menos amorfa, anónima y homogénea sino como una entidad singular y personalizada. Las "audiencias", ese significante que hacía serie con la radio, la televisión y la recepción de contenidos culturales, ceden hoy su lugar a los "usuarios", término que connota una mayor actividad en la relación mediática de plataformas. Esta inter-actividad va dejando rastros en cada micro-comportamiento, rastros conocidos como datos que, cual minería, podrán ser extraídos, analizados y explotados de acuerdo con las características de la plataforma y los objetivos del caso -en el que nos ocupa: su promoción como un servicio para los anunciantes y la optimización de la personalización de las recomendaciones (con la consecuente búsqueda de la renovación del atractivo de la plataforma para generar y retener usuarios), delineadas para cada individuo, con música "sólo para tus oídos"-

El sistema de recomendación, de esta suerte, responderá a un criterio complejo de articulación de variables que seleccionará automáticamente las canciones de sugerencia en base a una construcción del perfil en variación continua, como si la línea que van trazando los datos interactivos que pasan por el tamiz de los algoritmos dibujara una silueta que no cesa de actualizarse en nuevas siluetas. Se estaría así en presencia del modelo subjetivo que construye la plataforma, organizado en torno a un individuo interactivo consumidor y generador de datos digitales a partir de los cuales se diseña dinámicamente su perfil, con el que interactuará. Gilles Deleuze (1999) tenía un nombre para esto, asentado a comienzos de la década de 1990, cuando de la redificación informática de la vida cotidiana apenas teníamos unas lentas computadoras de escritorio y proyectos a futuro de desarrollo de autopistas de información: "Los individuos se han convertido en 'dividuales', y las masas, en muestras, datos" (p. 108). Si el individuo -insiste Pablo Rodríguez (2019) en un análisis del texto de Deleuze- se convierte en dividual mientras la masa se convierte en muestras y datos, "pareciera, pues, que lo dividual sería una nueva versión del individuo, digital, basada en cifras" (p. 451), una suerte de "doble informático" que "no sería exactamente un espejo, sino más bien una multiplicación, una fragmentación y explosión de datos, que luego, más tarde, encontrará al individuo del cual supuestamente provienen y al cual supuestamente vuelven. Lo dividual nombraría entonces ese largo proceso de mediación informacional" (Rodríguez, 2019, p. 452). La plataforma concibe así al sujeto-usuario a través de la confección algorítmica de su perfil como un in-dividuo informacional móvil, en el sentido amplio del término, no sólo en relación a su ubicación espacial sino en tanto que sus gustos y preferencias musicales (así como la afecto-emotividad concomitante), de los que se lleva su registro, análisis y actualización en tiempo real, son también entendidos como oscilantes y cambiantes -gustos y preferencias, por otra parte, a los que procurará anticiparse al mismo tiempo que se va ajustando a ellos, en una espiral incesante en la medida en que se retroalimente-.

Cabe precisar, en este punto, que semejante perfilización se compone de datos que no remiten exclusivamente a los comportamientos de un individuo, sino que se cruzan datos y perfiles de los comportamientos de múltiples individuos a partir de los cuales se establece la 
sugerencia -es lo que hemos visto a propósito de la hibridez de los procedimientos algorítmicos en el sistema de recomendación de Spotify-. Este hecho lleva a la investigadora brasileña Fernanda Bruno a plantear que el perfil "es un conjunto de trazos que no concierne a un individuo específico, sino que expresa las relaciones entre individuos, siendo más interpersonal que intrapersonal" (citado en Rodríguez, 2018, p. 20). Su principal objetivo -agrega- "no es producir un saber sobre un individuo identificable, sino usar un conjunto de informaciones personales para actuar sobre similares", en la búsqueda de "la probabilidad de manifestación de un factor (comportamiento, interés, trazo psicológico) en un cuadro de variables" (2018, p. 20). Se trata de un enfoque afín al que plantea Rodríguez en la cita que encabeza el presente artículo, al decir que:

No se trata de la identificación de un individuo, único e irrepetible, sede de una singularidad, sino del hecho de que eso que se individualiza es el resultado de las búsquedas estadísticas de millones de 'personas' que permiten saber qué desea 'esa' persona porque ese deseo emana de una función estadística que, cuantos más datos generales tiene, mejor puede identificar sus targets. (Rodríguez, 2019, p. 461)

En este sentido se puede entender, por caso, la campaña publicitaria "happy targeting", lanzada por Spotify en España en 2019 luego de un acuerdo con Renault, consistente en enviar un anuncio de promoción de la marca de la empresa de autos sólo en el momento en que la plataforma capta un estado de ánimo en el usuario que identifica como alegre (por ejemplo si se encuentra escuchando listas de reproducción como "Hits alegres", "Canta en la ducha" o "Despierta y sonríe”). La personalización del anuncio, así entendido, no quiere decir que me será destinado sólo a mí, sino a usuarios como yo (en este caso, usuarios emocional y contextualmente contentos, inferidos como tales). Por ello, sintetiza Patrick Vonderau (2017) en la misma línea de razonamiento que Bruno y Rodríguez, aunque la perfilización algorítmica ciertamente indica "un cambio de grandes agregados estadísticos hacia objetivos individuales particulares, ese 'objetivo' no debe ser equiparado con un ser humano individualizado sino con uno inferido. En lugar de ser usted, los objetivos son como usted' (p. 10).

Por último, resta por decir que lo dividual es para Deleuze el efecto, en el plano de la subjetividad, de los cruces emergentes entre las nuevas formas de saber-poder -formas reticulares y nómades, de un lado, en tanto se materializan en máquinas informáticas y digitales que se articulan en términos de redificación social y movilidad conectiva; formas lábiles, del otro, en cuanto tienden a invisibilizarse en flujos de información e instrucciones matemáticas-. Inspirado en la teoría de la individuación de Gilbert Simondon, pero atendiendo a las transformaciones socio-tecnológicas de finales del siglo XX, Deleuze (1999) sostiene que no se trata de concebir a los individuos como sujetos únicos, indivisos y estables en el tiempo, sino que habrá que pensarlos como subjetividades divisibles ${ }^{14} \mathrm{y}$ reductibles a representaciones de datos en un proceso continuo de individuación, a las que por lo tanto no se trataría de moldear sino de modular. Ahora bien, las características y el sentido de esta modulación relativa a los in-dividuos

\footnotetext{
14 Esta idea de una subjetividad divisible (dividual) guarda su afinidad con la noción de subjetividad distribuida propuesta por Anahid Kassabian (2013), definida como "una subjetividad no individual, un campo, pero un campo en el cual el poder se distribuye de manera desigual e impredecible, sobre el cual las diferencias no sólo son posibles sino requeridas, y a través del cual la información fluye, conduciendo a respuestas afectivas” (p. 25).
} 
perfilizados y las relaciones de poder en las que se inscriben, quedarán en todo caso pendientes de ser calibradas en un eventual próximo artículo.

Si hemos centrado este trabajo en el análisis de una de las plataformas de streaming musical ello se debe, como se anunció más arriba, no a la inexistencia de rasgos comunes entre algunas de ellas -en efecto, podría pensarse en Deezer como una compañía que construye su modelo económico en base a una estrategia freemium; o en Apple Music, como empresa que, compitiendo por una cuota de mercado global que le acerque a los ingresos por suscripción de Spotify, ha desarrollado en el último tiempo una estrategia de recomendación algorítmica que comprende, entre otras características, una lista de reproducción basada en el propio historial de escucha, actualizada semanalmente, llamada My New Music Mix y disponible en la sección For You, todo lo cual permitiría establecer puntos de contacto, así como de contraste, entre sus respectivos modelos subjetivos-. Pero más allá de la validez de un análisis comparado, que otros han realizado y habrán de realizar, aquella cautela aconsejada por Arrese (2004) a la hora de "universalizar" ideas, teorías o principios sobre contenidos mediáticos cuya variada naturaleza los ponía en riesgo de errar, y que nosotros hicimos extensiva a las plataformas de streaming musical haciendo foco en Spotify especialmente en cuanto a su forma (de generar ingresos, de captar y retener suscriptores, de tratar los datos, de construir un sujeto ideal), nos permitió observar en profundidad y detalle sus estrategias de -según las hemos denominado- embudo, filtro y brújula, es decir, las propiedades económicas, técnicas y subjetivas (o bien las relaciones entre mercado, tecnologías computacionales y usuarios, para decirlo con la definición de plataformas digitales de Eriksson et al.) cuya trama, además de servir de modelo a otras plataformas, constituye una fisonomía que no es sino uno de los perfiles de nuestro presente.

\section{Conclusiones}

Más allá del listado que se pueda hacer de las plataformas de streaming musical actualmente existentes, hay algunos servicios que prevalecen y se terminan imponiendo sobre otros, y no sólo desde el punto de vista económico, sino también -y quizás fundamentalmente- a nivel simbólico. Esto es lo que ha sucedido con Spotify, que se ha establecido como plataforma de streaming musical de referencia a escala global, siendo tanto en la actualidad como a lo largo de la última década la que más ingresos genera y mejor posición de mercado detenta, la que más usuarios activos tiene y mayor circulación social ostenta, hechos cuya importancia no reside únicamente en la ventaja comparativa respecto de las demás plataformas, sino en la posibilidad de reproducción y perpetuación en el tiempo que esta circunstancia habilita, pues como se ha detallado a propósito de la noción de "efecto de red", el crecimiento en volumen de usuarios puede redundar en mayores ingresos y en un mejor posicionamiento y mayor reconocimiento de la empresa-marca, lo que a su vez atraería nuevos usuarios, y mientras más numerosos sean los usuarios de una plataforma, más valiosa se vuelve esa plataformas para los demás (porque más usuarios generan más usuarios), lo que lleva a reforzar la posición dominante en una espiral con -según Srnicek- "tendencia natural a la monopolización". Es por ello que, tomando estos indicadores como punto de partida, hemos optado por un análisis en profundidad de Spotify, en lugar de hacer un estudio comparativo entre plataformas. Esto no nos impidió dar una definición abarcativa que remita a las plataformas de streaming musical en general. Pero la caracterización general de las plataformas de streaming musical fue el punto de partida sobre cuya base se procuró 
examinar en detalle el caso Spotify, a la luz de su mentada singularidad a escala global respecto de su adopción social y posición dominante de mercado.

Hemos recurrido a Eriksson et al. (2019) y a Srnicek (2018) para construir una definición general de las plataformas digitales y, a partir de allí, de las plataformas de streaming musical. Si en primer término aquellos nos decían que las plataformas digitales son "el eslabón perdido entre la computación y los negocios, un mercado en línea que une los intereses de las industrias y los usuarios" (p. 12), en segundo lugar Srnicek podía agregar que se trata de un nuevo tipo de empresa, "mucho más que empresas de Internet o empresas de tecnología, dado que pueden operar en cualquier parte, donde sea que tenga lugar la interacción digital” (p. 47). Y precisaba, al interior de esta caracterización, que las plataformas de streaming musical son plataformas de productos on-demand que transforman bienes tradicionales en servicios a cambio de una suscripción. Así entendidas, las plataformas de streaming musical serían constructos tecnoeconómicos mediados por las actividades de los usuarios, quienes accederían al servicio de contenidos a pedido por la vía de una suscripción. Funcionarían, asimismo, como el "terreno" sobre el que tienen lugar esas actividades, convirtiéndose así en el espacio digital privilegiado para el registro de la totalidad de los datos que emanan de ellas, pues como se dijo, las plataformas traducen la música y las inter-actividades en datos. Y dada la proliferación en la producción y circulación de esos datos, tanto en su tratamiento como en la búsqueda de ganancias los algoritmos desempeñan un papel central. Si bien los distintos tipos de plataformas desarrollan diferentes modos de tratamiento de esos datos - diferentes modos de extraerlos, analizarlos, utilizarlos y/o venderlos- y diferentes modos de organizar y perfilar su economía, con la finalidad de aumentar sus ingresos y obtener una rentabilidad.

Es así que, sobre esta base, el análisis de Spotify consistió en establecer y precisar las relaciones existentes entre economía, técnica y subjetividad, de cuyos cruces emergerían, según la caracterización de Eriksson et al., las especificidades de nuestro "eslabón perdido". Según hemos podido analizar, cabría sintetizar estas relaciones en lo que hemos denominado la modalidad de “embudos, filtros y brújulas": el embudo hace referencia al modelo de negocios de la plataforma, el filtro remite al modelo del sistema de recomendación basado en el llamado aprendizaje automático o machine learning, mientras la brújula representa la orientación y personalización para el usuario basada en la implementación del sistema de recomendación. Si las plataformas digitales suponen ya la emergencia de un nuevo modelo de negocios frente al estancamiento de la productividad basada en el intercambio de bienes, la lógica económica de Spotify se presenta como un rasgo específico al interior de ese modelo, una veta particular en la búsqueda de crecimiento y rentabilidad.

El modelo conocido como freemium (neologismo que resulta de la combinación de las palabras inglesas "free" y "premium"), que obtiene sus ingresos a través de la publicidad para los usuarios que no pagan por el servicio y a través del pago para quienes tienen una cuenta con abono, apuesta por un ingreso masivo de usuarios "free" que una vez en la plataforma puedan ser seducidos a convertirse en usuarios "premium”. Hemos visto cómo esta apuesta se inscribía en la fórmula "crecimiento primero, ganancias después": crecimiento de usuarios a través de un rápido acceso a una suscripción gratuita limitada en posibilidades de uso como puerta de entrada a un servicio de pago con mayores beneficios; crecimiento geográfico a través del desembarco y operación en nuevos países como modo de escalar en usuarios a nivel global y fortalecer el nombre de la empresa como una marca; crecimiento en la ampliación y diversificación de la oferta de contenidos, sumando canciones y artistas al catálogo musical e incorporando podcasts 
que hacen de la empresa una plataforma de audio más que una plataforma sólo musical, todo lo cual constituiría un método que prescribe tener pérdidas significativas como parte de una estrategia que busca, primero, crecer y diversificarse para asentarse y posicionarse, y como consecuencia, generar las condiciones para una mayor concentración del mercado que redunde finalmente en el crecimiento que verdaderamente importa, el de la tasa de ganancia. Ahora bien, queda por demostrar para la empresa, como hemos visto, si su modelo de negocios se volverá económicamente sostenible en el largo plazo. Todo indica -según hemos observado en los balances anuales de la compañía- que su efectiva estrategia de crecimiento, diversificación y posicionamiento no ha decantado aun en términos de rentabilidad. Pero en la medida del despliegue actual de la estrategia de captación, retención y crecimiento de su base de usuarios, un factor central para comprender el lugar que ocupa Spotify entre las plataformas de streaming musical ha sido -junto con los ya mencionados- el desarrollo de un singular sistema de recomendación, por medio del cual la plataforma configura una "experiencia de usuario" distintiva: su plus diferencial.

La "paradoja de elección" que podría suscitarse debido a la sobreabundancia de contenidos es así resuelta a través de la disposición de una serie de filtros que componen el sistema de recomendación. Esos filtros, a los que nos hemos referido como los tres modelos algorítmicos que habitan "en el corazón" de Spotify (el modelo basado en contenido, el modelo de filtrado colaborativo y el modelo de procesamiento del lenguaje natural), organizan, clasifican, segmentan, jerarquizan y analizan los datos que en cada interacción en la plataforma el usuario suministra, para devolverlos a la interfaz gráfica en forma de sugerencias personalizadas de escucha ("Especialmente para ti": "Descubrimiento semanal", "Tu radar de novedades", "Tu Daily Mix", "Tu Cara B", "Ir a radio de la canción", "Ir a artista de la canción", etc.). Estas sugerencias personalizadas son remitidas al perfil del usuario -creado y retroalimentado algorítmicamente a partir de la correlación y análisis de los datos almacenados-, con el cual el sujeto de la escucha entrará en relación. Es decir que a través del perfil, basado en la traza de movimientos virtuales pasados, se personalizan los contenidos a los que el sujeto tendrá acceso y se busca anticipar o predecir sus movimientos, gustos e intereses musicales futuros. Es a ese doble informático al que dimos en llamar, con Deleuze, dividual, es decir, la individuación digital del sujeto. De este modo, el sistema de recomendación se convierte en la brújula con la que "navegar en el mar de contenidos" que ofrece la plataforma. Y de allí que habría que pensar a Spotify, finalmente, menos como un intermediario que conecta individuos con archivos sonoros y más como un mediador que modifica el sentido de los elementos que se supone debe transportar.

\section{Referencias}

Arcila-Calderón, C., Sánchez-Holgado, P. y Ordóñez González K. (2019). Las plataformas de entretenimiento on-demand: detrás del Machine Learning de Netflix, HBO y Spotify. En Romero Rodríguez, L.M. y Rivera Rogel, D.E. (Coords.). La comunicación en el escenario digital. Actualidad, retos y prospectivas (pp. 645-669). Pearson. http://teccomunicacion.unsl.edu.ar/Tecno\%20I/2019/Teor\%EDas/Documentos/La_comunicacion_ en_el_escenario_digital.pdf

Arrese, A. (2004). Algunas consideraciones sobre la gestión de productos y contenidos de los medios. Comunicación y sociedad, XVII (2), 9-44. 
Becerra, M., Labate, C., Lozano, L., Marino, S. y Mastrini, G. (2013). Abordajes sobre el concepto de 'concentración'. En Mastrini, G., Bizberge, A. y de Charras, D. (Eds.). Las politicas de comunicación en el Siglo XXI. Nuevos y viejos desafios (pp. 139-174). La Crujía.

Chevalier Naranjo, S. (2021). El steaming, una segunda vida para la industria musical. Statista. https://es.statista.com/grafico/9156/ingresos-del-mercado-mundial-de-la-musica-grabada/

Chodos, A.T. (2019). What does music mean to Spotify? An essay on musical significance in the era of digital curation. INS AM: Journal of Contemporary Music, Art and Technology, 1 (2), 36-64.

Deleuze, G. (1999). Posdata sobre las sociedades de control. En Ferrer, Christian (Comp). El lenguaje libertario. Antología del pensamiento anarquista contemporáneo (pp. 105-110). Altamira.

Eriksson, M. (2018). Unpacking Online Streams. APRJA, 7, (1). https://doi.org/10.7146/aprja.v7i1.115066

Eriksson, M., Fleischer, R., Johansson, A., Snickars, P. y Vonderau, P. (2019). Spotify Teardown. Inside the Black Box of Streaming Music. MIT Press.

García, J. (2020). Quién está ganando la guerra del streaming de música. Xataka. https://www.xataka.com/empresas-y-economia/quien-esta-ganando-guerra-streamingmusica

IFPI (2021). Global Music Report 2021. State of the Industry. https://www.ifpi.org/wpcontent/uploads/2020/03/GMR2021_STATE_OF_THE_INDUSTRY.pdf

Kassabian, A. (2013). Introduction. Ubiquitous Listening: Affect, Attention and Distributed Subjectivity. University of California Press.

Lury, C. y Day, S. (2019). Algorithmic Personalization as a mode of individuation. Theory, Culture and Society, $O$ (0), 1-21. https://doi.org/10.1177/0263276418818888

Monzoncillo, J. M. (2011). Las nuevas televisiones: personalización e individualización. La televisión etiquetada. Nuevas audiencias y nuevos negocios (pp. 83-101). Planeta.

Nylund Hagen, A. (2015). Using Music Streaming Services: Practices, Experiences and the Lifeworld of Musicking. [Tesis doctoral, Faculty of Humanities, University of Oslo]. https://www.academia.edu/21823524/Using_Music_Streaming_Services_Practices_Experie nces_and_the_Lifeworld_of_Musicking

Ortelli, M. (2016). Radiohead. La banda del futuro. Página/12. https://www.pagina12.com.ar/diario/suplementos/radar/9-11510-2016-05-22.html

Pichl, M.; Zangerle, E. y Specht, G. (2015). Towards a context-aware music recommendation approach: what is hidden in the playlist name? IEEE 15th International Conference on Data Mining Workshop (pp. 1360-1365). DOI 10.1109/ICDMW.2015.145

Portugal, I., Alencar, P. y Cowan, D. (2018). The use of machine learning algorithms in recommender systems: A systematic review. arXiv, 4, 1-16. https://arxiv.org/ftp/arxiv/papers/1511/1511.05263.pdf

Prey, R. (2018). Nothing Personal. Algorithmic individuation on music streaming platforms. Media, Culture and Society, 40 (7), 1086-1100. Sage Publications. https://journals.sagepub.com/doi/full/10.1177/0163443717745147

Rodríguez, P. (2019). Las palabras en las cosas. Saber, poder y subjetivación entre algoritmos y biomoléculas. Cactus.

Rodríguez, P. (2018). Gubernamentalidad algorítmica. Sobre las formas de subjetivación en la sociedad de los metadatos. Revista Barda, 4, (6), 14-35. https://www.cefc.org.ar/assets/files/rodriguez.pdf 
Rus, C. (2020). Spotify va a por todas con el podcast: compra Gimlet Media, una de las principales redes de podcast a nivel mundial. Xataka. https://www.xataka.com/servicios/spotify-va-a-todas-podcastcompra-gimlet-media-principales-redes-podcasts-a-nivel-mundial

Sanjinés Flores, D.E. (2019). Sistema para la Minería de Opiniones. Avances en Informática y Automática. Duodécimo Workshop (pp. 97-109). https://gredos.usal.es/handle/10366/139439

Spotify for Artists (2019). How Fans Also Like' Works. https://artists.spotify.com/blog/howfans-also-like-works

Spotify Investors (2021). Press Release Details: Spotify Technology S.A. Announces Financial Results for First Quarter 2021. https://investors.spotify.com/financials/press-releasedetails/2021/Spotify-Technology-S.A.-Announces-Financial-Results-for-First-Quarter2021/default.aspx

Spotify Labs (2020). For Your Ears Only: Personalizing Spotify Home With Machine Learning. https://labs.spotify.com/2020/01/16/for-your-ears-only-personalizing-spotify-home-withmachine-learning/

Spotify Technology S.A. (2018). Prospectus. Form F-1 Registration Statement. United States Securities and Exchange Comission. https://www.sec.gov/Archives/edgar/data/1639920/000119312518063434/d494294df1.ht $\mathrm{m}$

Srnicek, N. (2018). Capitalismo de plataformas. Caja Negra.

Sweney, M. (2018). Slipping discs: music streaming revenues of $\$ 6.6 b n$ surpass CD sales. The Guardian. https://www.theguardian.com/technology/2018/apr/24/music-streaming-revenuesovertake-cds-to-hit-66bn

Terranova, T. (2017). "Red Stack Attack! Algoritmos, capital y la automatización del común”. Avanessian, A. y Reis, M. (Comps.). Aceleracionismo. Estrategias para una transición hacia el postcapitalismo. Caja Negra.

Vonderau, P. (2017). The Spotify Effect: Digital Distribution and Financial Growth. Television and New Media, 20, 1), 17. https://www.academia.edu/35208651/The_Spotify_Effect_Digital_Distribution_and_Finan cial_Growth

Wang, A. (2019). 'Spotify Teardown' Is The Book Spotify Didn't Want Published. Rolling Stone. https://www.rollingstone.com/pro/features/spotify-teardown-book-streaming-music790174/

Wikström, P. (2014). La industria musical en una era de distribución digital. C@MBIO.19 ensayos fundamentales sobre cómo internet está cambiando nuestras vidas. BBVA Open Mind. https://www.bbvaopenmind.com/libros/cambio-19-ensayos-fundamentales-sobre-comointernet-esta-cambiando-nuestras-vidas/

Yepes Vélez, A., López Batista V. y Moreno, M. (2019). Sistema de Recomendación de música Sensible al Contexto. Avances en Informática y Automática. Duodécimo Workshop (pp. 40-64). https://gredos.usal.es/handle/10366/139439 